\title{
Strategic Choice of Channel Structure in an Oligopoly
}

\author{
Lin Liu \\ Marshal School of Management \\ University of Southern California \\ X. Henry Wang \\ Department of Economics \\ University of Missouri-Columbia \\ and \\ Bill Z. Yang \\ College of Business Administration \\ Georgia Southern University
}

March 2011

\begin{abstract}
The traditional wisdom holds that the benefits of a decentralized channel structure arise from downstream competitive relationships. In contrast, Arya and Mittendorf (2007) showed that the value of decentralization can also arise from upstream interaction when the downstream firm conveys internal strife (decentralization) to an upstream external supplier. This paper extends the single firm centralization-decentralization choice model of Arya and Mittendorf (2007) to a strategic choice model in which all downstream competitors play a strategic centralization-decentralization game. We demonstrate that whether the main conclusions in the context of non-strategic choice of channel structure continue to hold when all firms play a centralization-decentralization game depends critically on the market structure of the upstream input market. Specifically, the conclusions are valid if all firms have exclusive upstream input suppliers but not so if the upstream input market is monopolized. Thus, whether the value of decentralization can arise from upstream interaction depends critically on the market structure of the upstream market.
\end{abstract}

JEL Codes: L22, D21

Keywords: Strategic Choice, Channel Structure, Oligopoly 


\section{Introduction}

Arya and Mittendorf (2007) offered a new point about the benefit of decentralization that internal inefficiency caused by transfer pricing associated with decentralization can force a firm's external input supplier to lower its supplier price to the extent that the decrease in input price overcomes the internal strife created by decentralization so that the firm ends up earning greater profits. This result is obtained in the context with the following three important assumptions. First, only one firm (in focus) chooses between centralization and decentralization while all of this firm's product-market competitors are assumed to be centralized. Second, the firm in question plays a strategic sequential-move game with its external input supplier while all of its competitors' external suppliers are assumed to be non-strategic. More specifically, the firm in focus chooses between centralization and decentralization and its external supplier sets a supplier price in anticipation of the firm's choice of distribution channel (centralization or decentralization). All other firms compete in the product market with the firm in focus but they are all centralized and they procure their external input from their supplier(s) at a price that is equal to the (constant) unit production cost. ${ }^{1}$ Third, each firm is assumed to procure an external input from its exclusive supplier.

The point made by Arya and Mittendorf is important and represents a significant advancement in our understanding of the mode of distribution channels. Like prices and quantities, internal channel structures are certainly deliberate choices that firms make. Accordingly, one natural area of inquiry along this line of research opened up by Arya and Mittenford lends to the following three questions: Do all competitors have an incentive to decentralize? Will the insights in a single firm choice model continue to be valid if all competitors engage in a choice on their channel structure and will strategic supplier price play a role? Does the market structure of the upstream market influence the value of decentralization arising from the upstream interaction? In this paper, we would like to explore the mode of distribution channels under a more general market structure by relaxing the three assumptions by Arya and Mittendorf (2007).

As all firms (the firm in focus and its rivals) become strategic in the choice of their internal channel

\footnotetext{
${ }^{1}$ Equivalently, all other competitors are centralized and produce all inputs internally.
} 
structure, the merit of decentralization becomes less intuitive. This is because when the rivals of the focal firm can choose decentralization the supplier of the focal firm might not want to cut into its supplier price as much as in the situation where all rivals of the focal firm are centralized as in Arya and Mittenford (2007). In other words, the supplier knows that the rivals of its downstream firm have an option to be decentralized and thus may compete less aggressively. Hence, it is not clear whether the value of decentralization can arise from upstream interaction when all firms convey internal strife (decentralization) to their upstream external suppliers. The answer to this question is puzzling as the rival's external supplier sets a supplier price in anticipation of the rival's choice of distribution channel (centralization or decentralization). That is the situation where all firms' external suppliers select their supplier prices strategically. It is because compared to the situation where the rival's supplier sets supply price to the (constant) unit production cost, the supplier of the firm in focus might be more reluctant to cut into its supply price if it knows the supplier of the rival can choose supply price above the production cost thus the downstream competition is even less competitive. In addition, the answer to the puzzle becomes even less intuitive as firms share a common supplier. It is because the common supplier has even less incentive to reduce the supplier price to the firm in focus which chooses decentralization as the supplier has alternative demand from downstream. The present paper sets out to explore the answers to this puzzle by extending the single firm centralization-decentralization choice model of Arya and Mittendorf (2007) to a strategic choice model in which all downstream competitors play a strategic centralization-decentralization game.

The questions posted above are obviously very closely linked and their answers could be sought in a single unified model. We will make the choice of distribution channel strategic in the sense that all final goods competitors make a choice on their distribution channel (centralized or decentralized). Moreover, all firms' external suppliers select their supplier prices strategically. As a result, the whole game involves three stages of strategic choices. In the first stage, all firms play a simultaneous move game in choosing between centralization and decentralization. In the second stage, supplier price(s) and internal transfer prices are chosen simultaneously. In the third stage, outputs for the final products are chosen simultaneously. As in Arya and Mittendorf (2007), the final stage may be either in a quantity game or a price game. In terms of the whole 
game being played, the key addition in our study here is the stage one game. We shall call the reduced game for stage one the centralization-decentralization game. As a contrast, we shall refer to the choice of centralization and decentralization in the model of Arya and Mittendorf (2007) as non-strategic in the sense that the firm in focus alone is contemplating a choice between centralization and decentralization.

In studying our centralization-decentralization game, we naturally do away with Arya and Mittendorf's assumption that all other final-good producers procure their external input at the constant unit cost of production. Instead, we assume all external suppliers play similar roles and choose their supplier prices strategically. In our base model of two firms (Section 2) it is assumed that the two final-good producers have different exclusive external suppliers. The main result we obtain from this setting is that the superiority of decentralization over centralization in the non-strategic choice model of Arya and Mittendorf (2007) continues to hold true in the strategic choice situation. Specifically, we show that choosing decentralization is a dominant strategy for both firms. Moreover, the decentralization outcome is superior to the centralization outcome for both firms; i.e., the two firms do better when both choose decentralization than when both choose centralization.

However, interestingly, we show that this conclusion can get reversed as firms share a common supplier. In other words, whether the value of decentralization can arise from upstream interaction depends critically on the market structure of the upstream market. Specifically, we consider a market structure in the upstream external input market that is the polar opposite to that in the base model. The second exploration area of the present paper (Sections 4 and 5) is on an important variation of our base model when the two firms share a common external input supplier. Obviously, such a supplier has more power over the downstream firms. It turns out that in this variation the result for the base model is substantially altered. We show that the decentralization outcome is no longer an equilibrium except for the case when goods are distant substitutes. For moderate or close substitutes, centralization is the only equilibrium outcome. Although the decentralization outcome is superior to the centralization outcome in that both firms reap higher profits when they are decentralized to force a collectively strong hand on the monopoly input supplier, such an outcome is not possible as the result of strategic choices when firms follow their own best interest. 
Returning to our base model, the main reason that decentralization is a dominant strategy for both firms rests in the effects on input prices decentralization can have. As in the non-strategic choice situation of Arya and Mittendorf (2007), when a firm switches from centralization to decentralization it forces its external supplier to lower its supplier price for fear of large drops in demand due to internal strife created by decentralization of the downstream firm. In the strategic choice situation of our base model, a switch from centralization to decentralization by one firm has this effect as well plus the additional effect that it induces the external supplier of the firm's product market competitor to raise its supplier price. ${ }^{2}$ Both effects on external input prices work to provide a firm with incentives to switch from centralization to decentralization. Moreover, these effects are the same in direction regardless of the distribution channel structure (centralized or decentralized) of the competitor, making decentralization dominant strategies in the centralizationdecentralization game.

Section 3 of the paper extends the base model of two firms to one with any fixed number of firms. The same intuitions continue to apply and the same results are shown to hold provided that goods are not close substitutes. This extends a similar result in Arya and Mittendorf (2007) to the strategic choice setting. In appendix B, we further show that the results of our base model continue to hold if the two firms compete via Bertrand price competition as opposed to Cournot quantity competition assumed in our base model.

The main reason for the common supplier model (Sections 4 and 5) to yield different results from the base model is that the aforementioned two effects on external input prices no longer work in the same direction. In the common supplier model, when a firm switches from centralization to decentralization the supplier price still decreases as in the base model. However, the supplier price for the firm's competitor also

\footnotetext{
${ }^{2}$ When a firm switches from centralization to decentralization, it becomes relatively less efficient in the sense that its internal transfer price is higher than the marginal cost of production for the internally produced input. This puts its lower division at a disadvantage in its competition with the centralized firm in the product markets since its cost from the internal input becomes higher relative to the centralized firm. This change in cost lowers the switching firm's demand for the input produced by its external supplier but raises the demand for the centralized firm which in turn raises the centralized firm's demand for the input of its external supplier. With linear demand curves, the switching firm's external supplier faces a more elastic demand while the competitor's external supplier faces a less elastic demand, resulting in a lower external input price for the switching firm and a higher external input price for the firm staying put.
} 
decreases. ${ }^{3}$ These two effects provide opposite incentives for the firm contemplating a switch. Moreover, the second effect provides an incentive for the firm's competitor to free ride by staying with centralization so as to enjoy the fruit of the former's action in receiving a lower external input price while retaining an advantage at the same time over the former by avoiding internal strife. As a result, centralization becomes a dominant strategy as long as the goods are moderate or close substitutes.

The issue of centralization versus decentralization has been a topic of study by researchers for decades. Dating back to Spengler (1950), researchers have long been interested in the comparison between centralized and decentralized distribution channels. McGuire and Staelin (1983) and Coughlan (1985) studied a manufacturer's choice on the structure of distribution channels. They showed that a decentralized channel such as selling through a middleman is more profitable for the manufacturer if products are close substitutes, whereas a centralized channel is more attractive for distant substitutes. Rey and Stiglitz (1995) found that manufacturers might use exclusive territories to reduce competition and decentralized channel is valuable as the channel competition is excessive. Gupta and Loulou (1998) demonstrated that decentralized channels might be more profitable for close substitutes when process innovation is taken into account. Trivedi (1998) extended the literature by analyzing a market structure with channel competition at both manufacturer and retailer levels and showed that manufacturers can no longer use decentralized channel as a cushion against competition. Deviating from the aforementioned papers which focus exclusively on price competition, Wang, Chen and $\mathrm{Wu}$ (2010) studied the implication as manufacturers are engaged in advertising competition. They found that a decentralized channel might benefit a manufacturer if it chooses to advertise and the rival chooses not to advertise. Most of the existing literature concludes that the benefits of a decentralized channel arise from downstream competition. As elaborated above, the present paper is most closely related to the work of Arya and Mittendorf (2007). Their study and our research look at the potential benefit decentralization can bring in the context of upstream connections.

\footnotetext{
${ }^{3}$ In the non-uniform pricing version of the model (Section 5), the second effect is present when the competitor is decentralized but disappears when the competitor is centralized. It results in asymmetrical equilibrium choices in the centralization-decentralization game.
} 
The rest of the paper is organized as follows. In Section 2, we present our base model with two firms producing two substituting goods and each having an exclusive external supplier. In Section 3, we extend the base model to one with any fixed number of firms producing substituting goods and each having an exclusive external supplier. In Section 4, we examine a variation of our base model in which the external input is monopolized and produced by a common supplier with uniform price. In Section 5, we relax the uniform price assumption in Section 4 by allowing the common external supplier to charge non-uniform prices to the two downstream firms. Section 6 concludes the paper. The paper has two appendices. Appendix A contains lemmas and proofs of some of the results in the paper. Appendix B is concerned with the base model but assumes that the two firms engage in Bertrand price competition in the final stage of the game.

\section{The Base Model: Two Firms with Exclusive External Suppliers}

The base model we consider has two firms (labeled as firm 1 and firm 2). The two firms face symmetric linear (inverse) demands, $p_{i}=a-q_{i}-\gamma q_{-i}, i=1,2$, where $p_{i}$ and $q_{i}$ are the price and quantity of firm i's final product, $a$ gauges the maximum (non-negative) price consumers are willing to pay for either good, and $\gamma \in[0,1]$ measures the level of substitutability between the two products. The two goods are independent if $\gamma=0$, and are perfect substitutes if $\gamma=1$. The cost of production is also symmetric between the two firms. One unit of output needs one unit of an internally manufactured input at a constant unit $\operatorname{cost} c_{I}$, and one unit of an externally manufactured input at a price set by the external supplier. The two firms have different exclusive external suppliers. (In Sections 4 and 5 we study a variation from the base model in which the firms have a common external supplier.) The external suppliers produce at the same constant unit $\operatorname{cost} c_{E}$. It is assumed that $c_{E}+c_{I}<a$.

Each firm chooses its structure of distribution channel - either a centralized channel or a decentralized channel. ${ }^{4}$ For a centralized firm, it procures the external input from its external supplier and internalizes the cost of production of the internal input to maximize its total profit. For a decentralized firm, it splits up into an

\footnotetext{
${ }^{4}$ For a decentralized firm, the lower division serves as the distributor of its final product.
} 
upper division and a lower division. The upper division produces the internal input and supplies it to the lower division at a transfer price. The lower division uses both the external input from the firm's external supplier and the internal input from the upper division to produce the final product. The lower division has zero additional cost. Each division maximizes its divisional profit. The profit of the firm is the total profit of the two divisions. $^{5}$

The two firms compete in the product market. In the base model (this section) they choose outputs via Cournot competition. For each firm, this decision is made by the firm if it chooses a centralized distribution channel; otherwise, the decision is made by the lower division of the firm. In Appendix B, we will report the results for the base model but assume that the firms engage in Bertrand price competition in the product market.

There are three stages in the game. In stage one, the two firms simultaneously decide on centralization or decentralization. In stage two, supplier prices and transfer prices for a decentralized firm are determined. In stage three, outputs are chosen by the centralized firm or by the lower division of a decentralized firm. We solve the game backward and hence the solution concept is the subgame perfect Nash equilibrium.

The first stage of the game described above has four possible outcomes corresponding to four subgames: both firms choose centralization (CC), both choose decentralization (DD), firm 1 chooses decentralization and firm 2 chooses centralization (DC), and firm 1 chooses centralization and firm 2 chooses decentralization (CD). These four subgames are analyzed and the corresponding results are presented in Lemma 1 to Lemma 4 in Appendix A.

Anticipating the equilibria in the four subgames as summarized in Lemmas 1-4, the two firms play a distribution channel game on centralization vs. decentralization in stage one of the three-stage game. We shall call the reduced game at stage one the centralization-decentralization game. The following proposition summarizes our findings about this game.

\footnotetext{
${ }^{5}$ We follow the treatment of Arya and Mittendorf (2007). The lower division is not an independent middleman because its profit belongs to the firm. This setup is different from those in Coughlan (1985) and McGuire and Staelin (1983).
} 
Proposition 1. With two firms each having an exclusive external supplier, the following results hold for the centralization-decentralization game.

(1) Decentralization is the dominant strategy for both firms for all $\gamma \in[0,1]$.

(2) The game is an efficient dominant-strategy game.

Proof: In Appendix A.

In the context of non-strategic choice between centralization and decentralization by a single firm, Arya and Mittendorf (2007) put forth the essential intuition that internal strife can create a wedge so that a firm's external supplier is forced to lower its supplier price in such a way that the downstream firm improves its profit relative to centralization. Proposition 1 establishes that this conclusion continues to hold in the strategic choice situation when there are two downstream firms both of which have their own exclusive external supplier and both choose between centralization and decentralization. Moreover, the equilibrium is efficient for the downstream firms in that both firms do better when both choose decentralization than when both choose centralization.

\section{N Firms with Exclusive External Suppliers}

In this section, we extend the base model studied in the previous section to one with $n(n>2)$ firms. As in the base model, each of the $n$ firms has an exclusive external supplier. The linear (inverse) demand function for firm $i$ is given by

$$
p_{i}=a-q_{i}-\gamma \sum_{j \neq i} q_{j}, \quad 0 \leq \gamma \leq 1, i=1,2, \ldots, n .
$$

Assume that $m$ of the $n$ firms choose to be centralized and the remaining $n-m$ firms choose to be decentralized. (This is a typical subgame in stage one of the three-stage game.) The external suppliers maximize their individual profit in choosing their supplier prices. The centralized firms and the lower divisions of the decentralized firms maximize profit by choosing quantities. Close examinations of the equilibrium input prices by the external suppliers, presented in Lemma 5 in Appendix A, lead to the following conclusions about 
these prices.

Corollary 1. (1) If a centralized firm switches to decentralization, its own supplier price decreases while all other firms' supplier prices increase. That is,

$$
s_{m-1, n-m+1}^{D}>s_{m, n-m}^{C}, \quad s_{m-1, n-m+1}^{C}>s_{m, n-m}^{C}, \text { and } s_{m-1, n-m+1}^{D}>s_{m, n-m}^{D} .
$$

(2) The supplier price for each centralized firm is greater than that of all decentralized firms. That is,

$$
s_{m, n-m}^{C}>s_{m, n-m}^{D}
$$

Proof: In Appendix A.

Part (1) of this corollary establishes that, no matter how many other firms are centralized, a centralized firm is able to lower the input price charged by its exclusive external supplier by switching to decentralization. This action at the same time raises the input prices of all other firms (centralized and decentralized) from their external suppliers. Part (2) of the corollary shows that centralized firms always have higher prices from their external suppliers than decentralized firms do.

The profit expressions in Lemma 5 imply that the number of centralized firms affects the profits of both types of firms proportionally. More specifically, the ratio of a centralized firm's profit over a decentralized firm's profit is independent of the number of centralized firms $(m)$. This fact helps to establish the following result about the profits for the two types of firms.

Corollary 2. With any number of centralized firms, in equilibrium every decentralized firm makes a larger profit than all centralized firms provided that $\gamma \leq 3 / 4$.

Proof: In Appendix A.

These two corollaries point to an incentive for a centralized firm to switch to decentralization. Our next main result (Proposition 2) shows that is indeed the case provided that goods are not close substitutes. 
When a firm switches from centralization to decentralization, it joins the ranks of a group of decentralized firms, all of which enjoy a cost advantage in the price of the external input but suffer from internal strife caused by decentralization. This is advantageous except in the case of close substitutes in which internal strife and fierce competition may eat away the advantage gained from a lower input price.

Proposition 2. With $n$ firms each having an exclusive external supplier, the following results hold for the centralization-decentralization game provided that $\gamma \leq 3 / 4$.

(1) Decentralization is the dominant strategy for all firms.

(2) The game is an efficient dominant-strategy game.

Proof: In Appendix A.

This proposition extends the results in Proposition 1 for two firms to the general case of $n$ firms. It shows that the results for the case of two firms continue to hold for any number of firms provided that the goods are not close substitutes $(\gamma \leq 3 / 4) .{ }^{6}$ Proposition 2 also generalizes a corresponding result in the case of non-strategic choice of distribution channel obtained by Arya and Mittendorf (2007). ${ }^{7}$

\section{Common External Supplier with Uniform Pricing}

In this section we consider an important variation from the base model by assuming that the two firms share a common external supplier. We have seen that with exclusive external suppliers, firms can weaken the pricing power of their suppliers and the cost position of their competitors by switching from centralization to decentralization. Here we examine how these powers are affected when the external input is monopolized. In this section we shall assume that the external supplier has to charge a uniform price to the two downstream firms regardless of what mode of distribution channel each adopts. In the next section, we examine the

\footnotetext{
${ }^{6}$ It may be worthwhile to point out that the condition on the substitution parameter $\gamma$ is not a necessary condition in that for larger values of $\gamma$ the equilibrium may be the same (although other outcomes may be supported in equilibrium).

${ }^{7}$ Note that the condition on the substitution parameter $\gamma$ in Proposition 2 is the same as that in Corollary 1 of Arya and Mittendorf (2007).
} 
common external supplier model by allowing the external supplier to charge possibly different prices to the two downstream firms. While the results are somewhat different from the one with uniform pricing, the essential conclusion established below that the existence of a common external supplier substantially alters a firm's incentive to become decentralized remains valid.

Like in the base model, the game here is played in three stages and there are four possible outcomes following stage one. We present results in Lemma 6 to Lemma 9 for the four subgames in Appendix A.

From Lemmas 6-9, we have the following relationships among the input prices set by the common external supplier for the two downstream firms under different distribution channel structures:

$$
s^{C C}-s^{C D}=\frac{(2-\gamma)\left(a-c_{E}-c_{I}\right)}{2(14+\gamma)}>0, \quad s^{D C}-s^{C D}=0, \quad s^{C D}-s^{D D}=\frac{\left(8-2 \gamma-\gamma^{2}\right)\left(a-c_{E}-c_{I}\right)}{(6-\gamma)(14+\gamma)}>0 .
$$

Hence, the supplier price is the highest when both firms are centralized and the lowest when both firms are decentralized.

It follows from the above that when a firm switches from centralization to decentralization, the supplier price by the external supplier becomes lower regardless of the choice of distribution mode by the other firm. That is, switching from centralization to decentralization always lowers the input price charged by the external supplier. The crucial difference between the situation here and that when firms have different external suppliers is that the benefit of a lowered supplier price is reaped by both firms. With a common external supplier, switching to decentralization by a firm does not raise the supplier price of its competitor but rather lowers it as well. As a result, if one firm chooses to be decentralized the other firm has an incentive to free ride by choosing to be centralized. By doing so, the latter reaps the benefit of a lower input price from the external supplier while still enjoys an advantage over its competitor by avoiding internal strife. This makes decentralization to be chosen only when the goods are distant substitutes (weak competition).

The next proposition shows the main result of this section.

Proposition 3. With the two firms sharing a common external supplier that charges a uniform price, the following results hold for the centralization-decentralization game. 
(1) If $0.3708<\gamma \leq 1$, then both firms have a dominant strategy $\mathrm{C}$ and the game is a prisoner's dilemma game.

(2) If $0 \leq \gamma \leq 0.3708$, then there are two Nash equilibria: $(C, C)$ and $(D, D)$.

Part (1) of this proposition confirms the intuition stated above that the incentive to free ride renders decentralization an inferior choice. However, both firms choosing decentralization is superior to both choosing centralization. That makes the game a prisoner's game, provided that the goods are moderate or close substitutes $(0.3708<\gamma \leq 1)$. When the goods are distant substitutes $(\gamma \leq 0.3708)$, the benefit from free riding is small due to the reduced benefit one enjoys from having a cost advantage over its competitor. In this case, equilibrium is attained as long as both firms make the same choice of distribution channel.

Proposition 3 shows that the result in the base model that (D, D) is a dominant-strategy equilibrium is no longer valid when the firms share a common external supplier. This is due to the crucial differences in the effects of one's switching from centralization to decentralization on its own supplier price and on its rival's supplier price under the two scenarios. It follows that whether a firm should adopt a decentralized distribution channel depends on whether such choice is a strategic variable as part of a game played between rival firms and also on the market environment the rivals are in (such as having exclusive external suppliers or sharing a common external supplier). In other words, whether the value of decentralization can arise from upstream interaction depends critically on the market structure of the upstream market.

The free ride due to the uniform price from the common external supplier renders decentralization an inferior option. The next section relaxes the uniform price assumption and shows that decentralization could still be a worse option under some condition.

\section{Common External Supplier with Non-uniform Pricing}

In this section, we analyze a variation of the common external supplier model studied in section 4 . In section 4, the external supplier is bound to set a uniform price for the two downstream firms. Here the supplier may charge non-uniform supplier prices to the two firms. Following a similar framework, the two firms choose 
to be centralized or decentralized in a three-stage game. We present the results for the four second-stage subgames by Lemma 10-13 in Appendix A.

Based on Lemmas 10-13, we can make the following statements about changes in input prices by the external supplier. Holding firm 2 as a centralized firm, if firm 1 switches from centralization to decentralization its external input price changes by

$$
s_{1}^{D C}-s_{1}^{C C}=-\frac{(2-\gamma)\left(a-c_{I}-c_{E}\right)}{12}<0
$$

whereas firm 2's external input price stays unchanged as $s_{2}^{D C}-s_{2}^{C C}=0$. This points to an advantage firm 1 can gain by switching to decentralization if firm 2 is centralized. Holding firm 2 as a decentralized firm, if firm 1 switches from centralization to decentralization its external input price changes by

$$
s_{1}^{D D}-s_{1}^{C D}=-\frac{(2-\gamma)\left(a-c_{I}-c_{E}\right)}{2(6-\gamma)}<0 ;
$$

while firm 2's external input price changes by

$$
s_{1}^{D D}-s_{1}^{C D}=-\frac{\gamma(2-\gamma)\left(a-c_{I}-c_{E}\right)}{12(6-\gamma)}<0 .
$$

In this case firm 1's switching from centralization to decentralization lowers the input prices charged to both firms. This result points to a lack of incentive to switch from centralization to decentralization when the rival firm is decentralized.

The above discussions indicate that when the common external supplier may charge different prices to the two downstream firms the centralization-decentralization game is likely to result in asymmetric choices in equilibrium. The next proposition confirms this result by showing that the game has two equilibria both involving asymmetric choices of distribution channel by the two firms.

Proposition 4. With the two firms sharing a common external supplier that may charge different prices, the following results hold for the centralization-decentralization game.

(1) There are two Nash equilibria: (C, D) and (D, C).

(2) Neither firm has a dominant strategy. 
When the two downstream firms have to rely on a common supplier who can charge different prices to them, decentralization is no longer a dominant strategy for either firm as in the case of uniform pricing (Proposition 3). This is because the incentive of the common supplier to cut into its prices is weakened due to the alternative demand sources. In other words, relying on a common suppler exacerbates competition between the two firms and excessive competition makes less favorable supplier terms. Interestingly, in contrast to Proposition 3, centralization is not a dominant strategy for either firm under non-uniform pricing. This is due to that non-uniform pricing by the input supplier removes the free-ride incentive for the downstream firms. Thus, the disadvantage of decentralization in this section is not driven by the free-rider issue present under uniform supply pricing. Rather, it is driven by the other firm's choice and the common external supplier setup. Specifically, if one firm chooses to be centralized, the other firm would choose decentralization because the benefit from the cut of supplier price still outweighs the cost even though the supplier term is less favorable. If one firm chooses to be decentralized, the other firm would choose the centralization strategy. This is because the decentralization choice for the latter is not beneficial as an effective means to further cut supplier prices. The benefit gleaned from decentralization is muted and becomes less attractive for this firm than the value brought by centralization which avoids internal strife.

Propositions 3 and 4 together show that monopolization of the upstream market weakens each downstream firm's benefit from decentralization. Thus, whether the value of decentralization can arise from upstream interaction depends critically on the market structure of the upstream market. The finding provides an interesting boundary for the novel result of benefit of decentralization proposed by Arya and Mittendorf (2007). This paper offers important managerial implications to managers when they procure external input from external suppliers by suggesting the need to more comprehensively understand the upstream market structure before they make the decision about the mode of distribution channel.

\section{Concluding Remarks}

We have shown that when two firms with exclusive external input suppliers are engaged in the 
strategic choice to be centralized or decentralized, the preference for decentralization persists as in the study by Arya and Mittendorf (2007). The equilibrium is Pareto efficient as the concessions in supplier prices offered by both firms' external suppliers overwhelm the internal strife (inefficiency) associated with decentralization. The conclusion holds both when the firms compete in quantities and in prices in the final goods markets. The conclusion also holds true with any fixed number of firms when every firm has an exclusive external input supplier provided that goods are not very close substitutes.

However, we have also shown that the validity of the above conclusion depends critically on the nature of competition in the upstream input market. In particular, if there is a single external input supplier (or equivalently the upstream input market is a collusive) then the above conclusion no longer holds. This is true both when the common external supplier charges a uniform price and when it practices price discrimination.

The topic of centralized or decentralized distribution channel deserves much future research. An extension of the framework of Arya and Mittendorf (2007) and this paper might integrate consumer search by considering a situation where manufacturers have to sell various products through a platform where they have to pay the platform slotting fees to be located at the prominent place. ${ }^{8}$ Under an optimal stopping rule, consumers search these prominent stores first and then decide whether to search the non-prominent ones. Armstrong, Vickers, and Zhou (2009) show that prominence introduces asymmetry retail demand and prices among competing firms. Thus, it might be interesting to know how the asymmetry in retail level competition influences manufacturer's choice on the structure of distribution channel.

Following most of the existing literature, this paper assumes the manufacturer to be the architect of the channel. A second interesting avenue to explore might be to consider the situation where the retailer can also influence the channel structure. There are a lot of examples in marketing that the retailer owns the retail space and can therefore decide whether to purchase from the manufacturer at a wholesale price and then resell the goods, or allow the manufacturer to set up a store-within-a-store. In the latter situation, the manufacturer decides the retail price. Jerath and Zhang (2010) conduct pioneer research on the issue of store-within-a-store

\footnotetext{
${ }^{8}$ In Macy or Bloomingdale, one can observe a number of department stores. The stores located near the entrance or other prominent positions might catch consumer's attention first.
} 
and find that the retailer tends to choose the stores-within-a-store arrangement for distant substitutes. Thus, according to our paper, the decentralized manufacturer is more likely to set up a store-within-a-store while the retailer would purchase from the centralized manufacturer and resell the products within its store. Under this expectation, it might be harder for the decentralized manufacturer to convince its supplier to cut into supplier price thus a decentralized manufacturer might not be profitable at all. By integrating the retailer's choice, the framework might allow us to examine the channel structure that emerges when the retailer and manufacturers can both make choices on the structure of the distribution channels.

Another interesting topic is to consider the situation where manufactures can strategically choose to be prominent or not within a platform. The non-prominent one conveys weakness to its supplier and attempts to obtain favorable supply terms. Knowing that consumers might not search these non-prominent manufacturers, the supplier might have to lower its supplier price. As a result, the non-prominent locations might not be a curse but become a blessing for manufacturers. 


\section{Appendix A: Lemmas and Proofs}

In this appendix we present our analyses of the subgames for the base model and its extension and variations, as well as proofs of propositions and corollaries. Our presentation follows the same order as the sections in the text.

\section{Two Firms with Exclusive External Suppliers:}

\section{Centralization subgame CC:}

In this subgame, the two exclusive external suppliers first simultaneously set their supplier prices $\mathrm{s}_{1}$ and $s_{2}$, respectively. Given the supplier prices, the two firms then simultaneously choose their retail outputs $\mathrm{q}_{1}$ and $\mathrm{q}_{2}$, respectively, to maximize their individual profit as follows:

$$
\begin{aligned}
& q_{1}\left(s_{1}, s_{2}\right)=\operatorname{argmax}_{q_{1}}\left(p_{1}-s_{1}-c_{I}\right) q_{1} \\
& q_{2}\left(s_{1}, s_{2}\right)=\operatorname{argmax}_{q_{2}}\left(p_{2}-s_{2}-c_{I}\right) q_{2}
\end{aligned}
$$

Solving (1) and (2) jointly, we obtain the firms' retail output quantities given the supplier prices.

In stage 2 of the game, the two exclusive suppliers decide the supplier prices to maximize their individual profits and solve:

$$
\begin{aligned}
& s_{1}=\operatorname{argmax}_{s_{1}}\left(s_{1}-c_{E}\right) q_{1}\left(s_{1}, s_{2}\right) \\
& s_{2}=\operatorname{argmax}_{s_{2}}\left(s_{2}-c_{E}\right) q_{2}\left(s_{1}, s_{2}\right)
\end{aligned}
$$

The solution to (3) and (4) yields the equilibrium supplier prices. Substituting these values back into (1) and (2) gives the firms' equilibrium quantities. The corresponding equilibrium prices as well as profits can be obtained from the demand functions. The results are summarized in the following lemma.

Lemma 1: In the equilibrium for subgame CC,

1) supplier prices are

$$
s_{1}^{C C}=s_{2}^{C C}=\frac{(2-\gamma)\left(a-c_{I}\right)+2 c_{E}}{4-\gamma} ;
$$


2) retail prices and quantities are

$$
p_{1}^{C C}=p_{2}^{C C}=\frac{\left(6-\gamma^{2}\right) a+2(1+\gamma)\left(c_{E}+c_{I}\right)}{(2+\gamma)(4-\gamma)}, \quad q_{1}^{C C}=q_{2}^{C C}=\frac{2\left(a-c_{E}-c_{I}\right)}{(2+\gamma)(4-\gamma)}
$$

3) firm profits are

$$
\pi_{1}^{C C}=\left(p_{1}^{C C}-s_{1}^{C C}-c_{I}\right) q_{1}^{C C}=\frac{4\left(a-c_{E}-c_{I}\right)^{2}}{(2+\gamma)^{2}(4-\gamma)^{2}}, \quad \pi_{2}^{C C}=\left(p_{2}^{C C}-s_{2}^{C C}-c_{I}\right) q_{2}^{C C}=\frac{4\left(a-c_{E}-c_{I}\right)^{2}}{(2+\gamma)^{2}(4-\gamma)^{2}}
$$

As expected, when both firms adopt a centralized distribution channel the solution is symmetric. Moreover, the supplier prices are above marginal costs $\left(c_{E}\right)$.

\section{Decentralization subgame DD:}

In the subgame DD, the suppliers and both firms' upper divisions first simultaneously set the supplier prices $s_{1}$ and $s_{2}$ and transfer prices $t_{1}$ and $t_{2}$, respectively. Then, the two lower divisions simultaneously choose their outputs $\mathrm{q}_{1}$ and $\mathrm{q}_{2}$ to maximize their division profit:

$$
\begin{aligned}
& q_{1}\left(s_{1}, s_{2}, t_{1}, t_{2}\right)=\operatorname{argmax}_{q_{1}}\left(p_{1}-s_{1}-t_{1}\right) q_{1} \\
& q_{2}\left(s_{1}, s_{2}, t_{1}, t_{2}\right)=\operatorname{argmax}_{q_{2}}\left(p_{2}-s_{2}-t_{2}\right) q_{2}
\end{aligned}
$$

Anticipating the lower divisions' behaviors as described by (5) and (6), the two exclusive suppliers decide $\mathrm{s}_{1}$ and $s_{2}$ and the upper divisions of the two firms set $t_{1}$ and $t_{2}$, respectively, to maximize their individual profits as follows:

$$
\begin{aligned}
& s_{1}=\operatorname{argmax}_{s_{1}}\left(s_{1}-c_{E}\right) q_{1}\left(s_{1}, s_{2}, t_{1}, t_{2}\right) \\
& s_{2}=\operatorname{argmax}_{s_{2}}\left(s_{2}-c_{E}\right) q_{2}\left(s_{1}, s_{2}, t_{1}, t_{2}\right) \\
& t_{1}=\operatorname{argmax}_{t_{1}}\left(t_{1}-c_{I}\right) q_{1}\left(s_{1}, s_{2}, t_{1}, t_{2}\right) \\
& t_{2}=\operatorname{argmax}_{t_{2}}\left(t_{2}-c_{I}\right) q_{2}\left(s_{1}, s_{2}, t_{1}, t_{2}\right)
\end{aligned}
$$

The solution to (7) - (10) leads to the equilibrium supplier prices and transfer prices. Substituting these values back into (5) and (6) yields the firms' equilibrium quantities, equilibrium retail prices and equilibrium profits for the two firms. These results are presented in Lemma 2. 
Lemma 2: In the equilibrium for subgame DD,

1) supplier prices are

$$
s_{1}^{D D}=s_{2}^{D D}=\frac{(2-\gamma)\left(a-c_{I}\right)+(4-\gamma) c_{E}}{2(3-\gamma)}
$$

2) transfer prices, retail prices and quantities are

$$
\begin{aligned}
& t_{1}^{D D}=t_{2}^{D D}=\frac{(2-\gamma)\left(a-c_{E}\right)+(4-\gamma) c_{I}}{2(3-\gamma)}, \\
& p_{1}^{D D}=p_{2}^{D D}=\frac{\left(5-\gamma^{2}\right) a+(1+\gamma)\left(c_{E}+c_{I}\right)}{(2+\gamma)(3-\gamma)}, \\
& q_{1}^{D D}=q_{2}^{D D}=\frac{a-c_{E}-c_{I}}{(2+\gamma)(3-\gamma)}
\end{aligned}
$$

3) firms' profits are ${ }^{9}$

$$
\begin{aligned}
& \pi_{1}^{D D}=\left(p_{1}^{D D}-s_{1}^{D D}-c_{I}\right) q_{1}^{D D}=\frac{\left(6-\gamma^{2}\right)\left(a-c_{E}-c_{I}\right)^{2}}{2(2+\gamma)^{2}(3-\gamma)^{2}} \\
& \pi_{2}^{D D}=\left(p_{2}^{D D}-s_{2}^{D D}-c_{I}\right) q_{2}^{D D}=\frac{\left(6-\gamma^{2}\right)\left(a-c_{E}-c_{I}\right)^{2}}{2(2+\gamma)^{2}(3-\gamma)^{2}} .
\end{aligned}
$$

As expected, when both firms adopt a decentralized distribution channel the solution is symmetric. Moreover, both the supplier prices and the transfer prices are above the respective marginal costs $\left(c_{E}\right.$ and $\left.c_{I}\right)$.

\section{$\underline{\text { Subgame with firm } 1 \text { decentralized and firm } 2 \text { centralized (DC): }}$}

In this subgame, first the external suppliers set their supplier prices $s_{1}$ and $s_{2}$, and simultaneously firm 1 's upper division decides the transfer price $t_{1}$. Then, the lower division of firm 1 and firm 2 simultaneously choose outputs $\mathrm{q}_{1}$ and $\mathrm{q}_{2}$ to solve the following problems:

$$
\begin{aligned}
& q_{1}\left(s_{1}, s_{2}, t_{1}\right)=\operatorname{argmax}_{q_{1}}\left(p_{1}-s_{1}-t_{1}\right) q_{1} \\
& q_{2}\left(s_{1}, s_{2}, t_{1}\right)=\operatorname{argmax}_{q_{2}}\left(p_{2}-s_{2}-c_{I}\right) q_{2}
\end{aligned}
$$

Anticipating the behaviors as described in (11) and (12), supplier 1 and supplier 2 choose $\mathrm{s}_{1}$ and $\mathrm{s}_{2}$,

\footnotetext{
${ }^{9}$ The profit of a decentralized firm is the sum of the profit of its two divisions.
} 
respectively, and firm 1's upper division selects transfer price $t_{1}$, to maximize their individual profits as follows:

$$
\begin{aligned}
& s_{1}=\operatorname{argmax}_{s_{1}}\left(s_{1}-c_{E}\right) q_{1}\left(s_{1}, s_{2}, t_{1}\right) \\
& s_{2}=\operatorname{argmax}_{s_{2}}\left(s_{2}-c_{E}\right) q_{2}\left(s_{1}, s_{2}, t_{1}\right) \\
& t_{1}=\operatorname{argmax}_{t_{1}}\left(t_{1}-c_{I}\right) q_{1}\left(s_{1}, s_{2}, t_{1}\right)
\end{aligned}
$$

Solving (13) - (15) jointly, we obtain the equilibrium supplier prices and transfer price. Substituting these values into (11) and (12) yields the firms' equilibrium quantities as well as the equilibrium prices and profits from demand functions.

Lemma 3. In the equilibrium for subgame DC,

1) supplier prices are

$$
S_{1}^{D C}=\frac{(2-r)(4+\gamma)\left(a-c_{I}\right)+\left(16+2 \gamma-\gamma^{2}\right) c_{E}}{2\left(12-\gamma^{2}\right)}, \quad S_{2}^{D C}=\frac{(2-\gamma)(3+\gamma)\left(a-c_{I}\right)+(6+\gamma) c_{E}}{12-\gamma^{2}}
$$

2) transfer price in firm 1 , retail prices and quantities are

$$
\begin{aligned}
& t_{1}^{D C}=\frac{(2-r)(4+\gamma)\left(a-c_{E}\right)+\left(16+2 \gamma-\gamma^{2}\right) c_{I}}{2\left(12-\gamma^{2}\right)} \\
& p_{1}^{D C}=\frac{(4+\gamma)\left(5-\gamma^{2}\right) a+\left(4+7 \gamma+2 \gamma^{2}\right)\left(c_{E}+c_{I}\right)}{(2+\gamma)\left(12-\gamma^{2}\right)}, \quad p_{2}^{D C}=\frac{(3+\gamma)\left(6-\gamma^{2}\right) a+\left(6+6 \gamma+\gamma^{2}\right)\left(c_{E}+c_{I}\right)}{(2+\gamma)\left(12-\gamma^{2}\right)} \\
& q_{1}^{D C}=\frac{(4+\gamma)\left(a-c_{E}-c_{I}\right)}{(2+\gamma)\left(12-\gamma^{2}\right)}, \quad q_{2}^{D C}=\frac{2(3+\gamma)\left(a-c_{E}-c_{I}\right)}{(2+\gamma)\left(12-\gamma^{2}\right)}
\end{aligned}
$$

3) firm profits are

$$
\begin{aligned}
& \pi_{1}^{D C}=\left(p_{1}^{D C}-s_{1}^{D C}-c_{I}\right) q_{1}^{D C}=\frac{(4+\gamma)^{2}\left(6-\gamma^{2}\right)\left(a-c_{E}-c_{I}\right)^{2}}{2(2+\gamma)^{2}\left(12-\gamma^{2}\right)^{2}} \\
& \pi_{2}^{D C}=\left(p_{2}^{D C}-s_{2}^{D C}-c_{I}\right) q_{2}^{D C}=\frac{4(3+\gamma)^{2}\left(a-c_{E}-c_{I}\right)^{2}}{(2+\gamma)^{2}\left(12-\gamma^{2}\right)^{2}}
\end{aligned}
$$

Both firms' suppliers charge above their marginal cost. Firm 1's transfer price is above the marginal cost of the internally produced input. As expected, the solution for this subgame is asymmetric. 
Subgame with firm 1 centralized and firm 2 decentralized (CD):

Results for subgame CD are immediately obtainable from Lemma 3 by switching the positions between the two firms. Thus we have

Lemma 4. In the equilibrium for subgame $C D$,

3) supplier prices are

$$
s_{1}^{C D}=\frac{(2-\gamma)(3+\gamma)\left(a-c_{I}\right)+(6+\gamma) c_{E}}{12-\gamma^{2}}, \quad S_{2}^{C D}=\frac{(2-r)(4+\gamma)\left(a-c_{I}\right)+\left(16+2 \gamma-\gamma^{2}\right) c_{E}}{2\left(12-\gamma^{2}\right)}
$$

4) transfer price in firm 2 , retail prices and quantities are

$$
\begin{aligned}
& t_{2}^{C D}=\frac{(2-r)(4+\gamma)\left(a-c_{E}\right)+\left(16+2 \gamma-\gamma^{2}\right) c_{I}}{2\left(12-\gamma^{2}\right)} \\
& p_{1}^{C D}=\frac{(3+\gamma)\left(6-\gamma^{2}\right) a+\left(6+6 \gamma+\gamma^{2}\right)\left(c_{E}+c_{I}\right)}{(2+\gamma)\left(12-\gamma^{2}\right)}, \quad p_{2}^{C D}=\frac{(4+\gamma)\left(5-\gamma^{2}\right) a+\left(4+7 \gamma+2 \gamma^{2}\right)\left(c_{E}+c_{I}\right)}{(2+\gamma)\left(12-\gamma^{2}\right)} \\
& q_{1}^{C D}=\frac{2(3+\gamma)\left(a-c_{E}-c_{I}\right)}{(2+\gamma)\left(12-\gamma^{2}\right)}, \quad q_{2}^{C D}=\frac{(4+\gamma)\left(a-c_{E}-c_{I}\right)}{(2+\gamma)\left(12-\gamma^{2}\right)}
\end{aligned}
$$

3) firm profits are

$$
\begin{aligned}
& \pi_{1}^{C D}=\left(p_{1}^{C D}-s_{1}^{C D}-c_{I}\right) q_{1}^{C D}=\frac{4(3+\gamma)^{2}\left(a-c_{E}-c_{I}\right)^{2}}{(2+\gamma)^{2}\left(12-\gamma^{2}\right)^{2}} \\
& \pi_{2}^{C D}=\left(p_{2}^{C D}-s_{2}^{C D}-c_{I}\right) q_{2}^{C D}=\frac{(4+\gamma)^{2}\left(6-\gamma^{2}\right)\left(a-c_{E}-c_{I}\right)^{2}}{2(2+\gamma)^{2}\left(12-\gamma^{2}\right)^{2}} .
\end{aligned}
$$

\section{Proof of Proposition 1:}

The centralization-decentralization game is represented by the following game matrix:

Firm 2

Firm 1

\begin{tabular}{|c|c|c|}
\hline & $\mathrm{C}$ & $\mathrm{D}$ \\
\hline $\mathrm{C}$ & $\left(\pi_{1}^{C C}, \pi_{2}^{C C}\right)$ & $\left(\pi_{1}^{C D}, \pi_{2}^{C D}\right)$ \\
\hline $\mathrm{D}$ & $\left(\pi_{1}^{D C}, \pi_{2}^{D C}\right)$ & $\left(\pi_{1}^{D D}, \pi_{2}^{D D}\right)$ \\
\hline
\end{tabular}

Consider first that firm 2 is centralized (first column of the above matrix). If firm 1 switches from centralization to decentralization, by Lemmas 1 and 3, the change in price from its supplier is 


$$
s_{1}^{D C}-s_{1}^{C C}=\frac{-(2-\gamma)\left(8-\gamma^{2}\right)\left(a-c_{I}\right)-\left(32-2 \gamma-3 \gamma^{2}\right) c_{E}}{2(4-\gamma)\left(12-\gamma^{2}\right)}<0 .
$$

Meanwhile, the supplier price of firm 2 is also affected and changes by

$$
s_{2}^{D C}-s_{2}^{C C}=\frac{\gamma(2-\gamma)\left(a-c_{E}-c_{I}\right)}{(4-\gamma)\left(12-\gamma^{2}\right)}>0 .
$$

Hence, when firm 1 switches from centralization to decentralization while firm 2 stays centralized, the former will receive a lower price from its external supplier while the other firm will see the price from its external supplier raised. ${ }^{10}$ These effects combine to increase the profit of firm 1 as confirmed by

$$
\pi_{1}^{D C}-\pi_{1}^{C C}=\frac{(2-\gamma)\left(12+6 \gamma-6 \gamma^{2}+\gamma^{3}\right)}{2(2+\gamma)^{2}(3-\gamma)^{2}(4-\gamma)^{2}}\left(a-c_{E}-c_{I}\right)^{2}>0 .
$$

Now suppose firm 2 is decentralized (second column of the above matrix). If firm 1 switches from centralization to decentralization, by Lemmas 2 and 4, the change in price from its supplier is

$$
s_{1}^{D D}-s_{1}^{C D}=\frac{-(2-\gamma)\left(6-\gamma^{2}\right)\left(a-c_{I}\right)-\left(32-2 \gamma-3 \gamma^{2}\right) c_{E}}{2(3-\gamma)\left(12-\gamma^{2}\right)}<0 .
$$

Meanwhile, the supplier price of firm 2 is also affected and changes by

$$
s_{2}^{D D}-s_{2}^{C D}=\frac{\gamma(2-\gamma)\left(a-c_{E}-c_{I}\right)}{2(3-\gamma)\left(12-\gamma^{2}\right)}>0 .
$$

Hence, when firm 1 switches from centralization to decentralization while firm 2 stays decentralized, the former will receive a lower price from its external supplier while the other firm will see the price from its external supplier raised. ${ }^{11}$ These effects combine to increase the profit of the first firm as confirmed by

\footnotetext{
${ }^{10}$ An explanation of these changes in supplier prices can be obtained by looking at the changes in the elasticities of the derived demands the two external input suppliers face. By comparing the solutions for $\left(q_{1}, q_{2}\right)$ for (1) and (2) and for (11) and (12), we find that when firm 1 switches from centralization to decentralization and firm 2 stays centralized the demand for firm 1's external input supplier changes by $2\left(c_{I}-t_{1}\right) /\left(4-\gamma^{2}\right)$ while demand for firm 2's external input supplier changes by $\gamma\left(t_{1}-c_{I}\right) /\left(4-\gamma^{2}\right)$; the former change is negative while the latter change is positive. These changes represent a parallel downward shift in the demand for firm 1's external input supplier and a parallel upward shift in the demand for firm 2's external input supplier. As a result, the demand for firm 1's external input supplier becomes more elastic while the demand for firm 2's external input supplier becomes less elastic. Corresponding, in equilibrium, firm 1's external input supplier lowers its price while firm 2's raises its price.

${ }^{11}$ A similar explanation exists as in the case when firm 2 stays centralized. More specifically, by comparing the solutions for $\left(q_{1}, q_{2}\right)$ for (5) and (6) and for the corresponding two problems (not provided in the text) in subgame CD, we find that when firm 1 switches from centralization to decentralization while firm 2 stays decentralized the demand for firm 1's external input supplier changes by $2\left(c_{I}-t_{1}\right) /\left(4-\gamma^{2}\right)<0$ while demand for firm 2's external input supplier changes by $2\left(t_{1}-c_{I}\right) /\left(4-\gamma^{2}\right)>0$. These changes make the demand for firm 1's external input supplier more elastic and the
} 


$$
\pi_{1}^{D D}-\pi_{1}^{C D}=\frac{216-144 \gamma^{2}+22 \gamma^{4}-\gamma^{6}}{2(2+\gamma)^{2}(3-\gamma)^{2}\left(12-\gamma^{2}\right)^{2}}\left(a-c_{E}-c_{I}\right)^{2}>0 .
$$

The above discussions stipulate that, for each firm, decentralization is better than centralization given either mode of distribution channel by the other firm. Hence, decentralization is a dominant strategy for both firms in the centralization-decentralization game.

Moreover, from Lemmas 1 and 2, the difference between the supplier prices under centralization and decentralization for both firms $(i=1,2)$ is

$$
s_{i}^{C C}-s_{i}^{D D}=\frac{(2-\gamma)^{2}\left(a-c_{E}-c_{I}\right)}{2(3-\gamma)(4-\gamma)}>0 .
$$

It follows both external suppliers charge a lower price when both downstream firms are decentralized than when both are centralized. This is directly responsible for the result that both downstream firms $(i=1,2)$ earn a higher profit when both choose decentralization as opposed to when both choose centralization, as shown by

$$
\pi_{i}^{D D}-\pi_{i}^{C C}=\frac{(2-\gamma)\left(12+6 \gamma-6 \gamma^{2}+\gamma^{3}\right)}{2(2+\gamma)^{2}(3-\gamma)^{2}(4-\gamma)^{2}}\left(a-c_{E}-c_{I}\right)^{2}>0, \text { for } i=1,2 .
$$

Hence, it is a dominant strategy for both firms to choose decentralization. That is, the unique Nash equilibrium of the centralization-decentralization game is (D, D). Moreover, the equilibrium is Pareto efficient. The game is therefore an efficient dominant-strategy game. ${ }^{12}$

\section{N Firms with Exclusive External Suppliers:}

We solve the three-stage game backward. In stage 3 , centralized firms $(i=1, \ldots, m)$ and the lower divisions of decentralized firms $(j=m+1, \ldots, n)$ choose their outputs simultaneously to solve the following problems:

$$
\begin{aligned}
& q_{i}=\operatorname{argmax}_{q_{i}}\left(p_{i}-s_{i}-c_{I}\right) q_{i} \\
& q_{j}=\operatorname{argmax}_{q_{j}}\left(p_{j}-s_{j}-t_{j}\right) q_{j},
\end{aligned}
$$

demand for firm 2's external input supplier less elastic, resulting in firm 1's external input supplier lowering its price and firm 2's external input supplier raising its price.

${ }^{12}$ Wang and Yang (2003) provide a classification of $2 \times 2$ games. 
where $t_{j}$ denotes the transfer price in decentralized firm $j$. In stage 2 , external suppliers $(i=1, \ldots, m ; j=m+$ $1, \ldots, n)$ choose their supplier prices and the upper divisions of decentralized firms $(j=m+1, \ldots, n)$ choose their transfer prices to solve the following problems:

$$
\begin{aligned}
& s_{i}=\operatorname{argmax}_{s_{i}}\left(s_{i}-c_{E}\right) q_{i}\left(s_{i}, s_{j}, t_{j}\right) \\
& s_{j}=\operatorname{argmax}_{s_{j}}\left(s_{j}-c_{E}\right) q_{j}\left(s_{i}, s_{j}, t_{j}\right) \\
& t_{j}=\operatorname{argmax}_{t_{j}}\left(t_{j}-c_{I}\right) q_{j}\left(s_{i}, s_{j}, t_{j}\right)
\end{aligned}
$$

The solutions of (18) to (20) yield the equilibrium supplier prices and transfer prices. Substituting these values back into (16) and (17), we obtain the firms' equilibrium quantities, and then the equilibrium prices and profits from the demand functions. The next lemma presents these values.

Lemma 5. ${ }^{13}$ With $m$ centralized firms, $n-m$ decentralized firms and each having an exclusive external supplier, in equilibrium

1) the supplier price for each centralized firm is

$$
S_{m, n-m}^{C}=\frac{\left(12-14 \gamma+6 n \gamma+4 \gamma^{2}-3 n \gamma^{2}\right)\left(a-c_{I}\right)+\left(12-20 \gamma+2 m \gamma+10 n \gamma+8 \gamma^{2}-2 m \gamma^{2}-8 n \gamma^{2}+m n \gamma^{2}+2 n \gamma^{2}\right) c_{E}}{24-34 \gamma+2 m \gamma+16 n \gamma+12 \gamma^{2}-2 m \gamma^{2}-11 n \gamma^{2}+m n \gamma^{2}+2 n^{2} \gamma^{2}} ;
$$

2) the supplier price for each decentralized firm is

$$
S_{m, n-m}^{D}=\frac{\left(8-10 \gamma+4 n \gamma+3 \gamma^{2}-2 n \gamma^{2}\right)\left(a-c_{I}\right)+\left(16-24 \gamma+2 m \gamma+12 n \gamma+9 \gamma^{2}-2 m \gamma^{2}-9 n \gamma^{2}+m n \gamma^{2}+2 n \gamma^{2}\right) c_{E}}{24-34 \gamma+2 m \gamma+16 n \gamma+12 \gamma^{2}-2 m \gamma^{2}-11 n \gamma^{2}+m n \gamma^{2}+2 n^{2} \gamma^{2}}
$$

3) each centralized firm's profit is

$$
\pi_{m, n-m}^{C}=\frac{(2-2 \gamma+n \gamma)^{2}(6-4 \gamma+3 n \gamma)^{2}\left(a-c_{E}-c_{I}\right)^{2}}{(2-\gamma+n \gamma)^{2}\left(24-34 \gamma+2 m \gamma+16 n \gamma+12 \gamma^{2}-2 m \gamma^{2}-11 n \gamma^{2}+m n \gamma^{2}+2 n^{2} \gamma^{2}\right)^{2}}
$$

4) each decentralized firm's profit is

$$
\pi_{m, n-m}^{D}=\frac{(2-2 \gamma+n \gamma)(4-3 \gamma+2 n \gamma)^{2}\left(6-6 \gamma+3 n \gamma+\gamma^{2}-n \gamma^{2}\right)\left(a-c_{E}-c_{I}\right)^{2}}{(2-\gamma+n \gamma)^{2}\left(24-34 \gamma+2 m \gamma+16 n \gamma+12 \gamma^{2}-2 m \gamma^{2}-11 n \gamma^{2}+m n \gamma^{2}+2 n^{2} \gamma^{2}\right)^{2}} .
$$

\footnotetext{
${ }^{13}$ Due to their messy expressions and not being explicitly used in our discussions below, we do not present the equilibrium retail prices and quantities.
} 


\section{Proof of Corollary 1:}

If a centralized firm switches to decentralization, its supplier price will change by (assuming all other firms stay the same in their choice of distribution channel)

$$
\begin{gathered}
s_{m-1, n-m+1}^{D}-s_{m, n-m}^{C}= \\
\frac{-(2-\gamma)\left(a-c_{I}-c_{E}\right)\left[48+4(m+14 n-26) \gamma+2\left(39-3 m-42 n+2 m n+10 n^{2}\right) \gamma^{2}+\left(-20+2 m+33 n-3 m n+m n^{2}-16 n^{2}+2 n^{3}\right) \gamma^{3}\right]}{\left[24-34 \gamma+2(m-1) \gamma+16 n \gamma+12 \gamma^{2}-2(m-1) \gamma^{2}-11 n \gamma^{2}+(m-1) n \gamma^{2}+2 n^{2} \gamma^{2}\right]\left(24-34 \gamma+2 m \gamma+16 n \gamma+12 \gamma^{2}-2 m \gamma^{2}-11 n \gamma^{2}+m n \gamma^{2}+2 n^{2} \gamma^{2}\right)}
\end{gathered}
$$

The sign of this difference is opposite of the bracketed terms in the numerator above. Among the four terms in the bracketed expression in the numerator above, the second term is always positive, the third term is negative only when $\mathrm{n}=2$ with the lowest value at -5 ; the last term is negative only for $\mathrm{n}$ from 2 to 5 with the lowest value at -16 . Since the first term (48) is greater than all the possible negative values added, the entire expression is always positive. Hence, $s_{m-1, n-m+1}^{D}>s_{m, n-m}^{C}$. This proves the first statement in part (1) of Corollary 1.

Treating $\mathrm{m}$ as a continuous variable and differentiating the expression for $s_{m, n-m}^{c}$ in part (1) of Lemma 5 with respect to $\mathrm{m}$, we have

$$
\frac{\partial s_{m, n-m}^{C}}{\partial m}=-\frac{\gamma(2-2 \gamma+n \gamma)\left(12-14 \gamma+6 n \gamma+4 \gamma^{2}-3 n \gamma^{2}\right)\left(a-c_{I}-c_{E}\right)}{\left(24-34 \gamma+2 m \gamma+16 n \gamma+12 \gamma^{2}-2 m \gamma^{2}-11 n \gamma^{2}+m n \gamma^{2}+2 n^{2} \gamma^{2}\right)^{2}}<0 .
$$

Since the above holds for all $\mathrm{m}$, it follows that $s_{m-1, n-m+1}^{C}>s_{m, n-m}^{C}$. Similarly, differentiating the expression for $s_{m, n-m}^{D}$ in part (2) of Lemma 5 yields

$$
\frac{\partial s_{m, n-m}^{D}}{\partial m}=-\frac{\gamma(2-2 \gamma+n \gamma)\left(8-10 \gamma+4 n \gamma+3 \gamma^{2}-2 n \gamma^{2}\right)\left(a-c_{I}-c_{E}\right)}{\left(24-34 \gamma+2 m \gamma+16 n \gamma+12 \gamma^{2}-2 m \gamma^{2}-11 n \gamma^{2}+m n \gamma^{2}+2 n^{2} \gamma^{2}\right)^{2}}<0 .
$$

It follows that $s_{m-1, n-m+1}^{D}>s_{m, n-m}^{D}$. That completes the proof for part (1) of Corollary 1.

Applying Lemma 5, the difference between the supplier price for each centralized firm and that for each decentralized firms is

$$
S_{m, n-m}^{C}-S_{m, n-m}^{D}=\frac{(2-\gamma)(2+(n-1) \gamma)\left(a-c_{I}-c_{E}\right)}{24-34 \gamma+2 m \gamma+16 n \gamma+12 \gamma^{2}-2 m \gamma^{2}-11 n \gamma^{2}+m n \gamma^{2}+2 n^{2} \gamma^{2}}>0 .
$$

This implies that given any number of centralized firms $(m)$, each decentralized firm receives a lower price from its external supplier than every centralized firm. Hence, part (2) of Corollary 1 is proved. 


\section{Proof of Corollary 2:}

From the expressions for $\pi_{m, n-m}^{c}$ and $\pi_{m, n-m}^{D}$ in parts (3) and (4) of Lemma 5, we have ${ }^{14}$

$$
\frac{\pi_{m, n-m}^{c}}{\pi_{m, n-m}^{D}}=\frac{(2-2 \gamma+n \gamma)(6-4 \gamma+3 n \gamma)^{2}}{\left(6-6 \gamma+3 n \gamma+\gamma^{2}-n \gamma^{2}\right)(4-3 \gamma+2 n \gamma)^{2}} .
$$

Denote this ratio by $g(n, \gamma)$. For $\gamma=0, g(n, \gamma)=3 / 4$ for all $\mathrm{n}$, implying that $\pi_{m, n-m}^{c}<\pi_{m, n-m}^{D}$ for all $\mathrm{m}$ and $\mathrm{n}$ if $\gamma=0$. The proposition is therefore proven if we can show that $\pi_{m, n-m}^{c}<\pi_{m, n-m}^{D}$ holds true for all $0<\gamma \leq 3 / 4$, all $n \geq 2$ and all $m \leq n$. We prove this by showing that $g(n, \gamma)<1$ for all $0<\gamma \leq 3 / 4$ and all $n \geq 2$.

We first show that $g(n, \gamma)$ is strictly increasing in $\mathrm{n}$ for all $\gamma \in(0,1]$. Treating $\mathrm{n}$ as a continuous variable and taking derivative of $g(n, \gamma)$ with respect to $n$, we obtain this derivative as given by

$$
\frac{(6-4 \gamma+3 n \gamma) \gamma^{2}\left[24+4(6 n-11) \gamma+6\left(5-5 n+n^{2}\right) \gamma^{2}-\left(8-11 n+4 n^{2}\right) \gamma^{3}\right]}{\left(6-6 \gamma+3 n \gamma+\gamma^{2}-n \gamma^{2}\right)^{2}(4-3 \gamma+2 n \gamma)^{3}} \text {. }
$$

The sign of this expression is obviously the same as the sign of

$$
24+4(6 n-11) \gamma+6\left(5-5 n+n^{2}\right) \gamma^{2}-\left(8-11 n+4 n^{2}\right) \gamma^{3}
$$

Since $6 n-11>0$ for $n \geq 2$, we have, for all $\gamma \in(0,1]$,

$$
\begin{aligned}
& 24+4(6 n-11) \gamma+6\left(5-5 n+n^{2}\right) \gamma^{2}-\left(8-11 n+4 n^{2}\right) \gamma^{3} \\
& >24 \gamma^{2}+4(6 n-11) \gamma^{2}+6\left(5-5 n+n^{2}\right) \gamma^{2}-\left(8-11 n+4 n^{2}\right) \gamma^{3} \\
& =\left(10-6 n+6 n^{2}\right) \gamma^{2}-\left(8-11 n+4 n^{2}\right) \gamma^{3}=\left(2+5 n+2 n^{2}\right) \gamma^{2}+\left(8-11 n+4 n^{2}\right)\left(\gamma^{2}-\gamma^{3}\right) \\
& \geq\left(2+5 n+2 n^{2}\right) \gamma^{2}>0,
\end{aligned}
$$

where the second to last inequality uses the fact that $8-11 n+4 n^{2}>0$ for all $n \geq 1$. It follows that $g(n, \gamma)$ is strictly increasing in $\mathrm{n}$ for all $\gamma \in(0,1]$.

It is straightforward to verify that $\lim _{n \rightarrow \infty} g(n, \gamma)=\frac{9}{4(3-\gamma)}$. Combining the fact this limit is less than or equal to 1 if and only if $\gamma \leq 3 / 4$ with the established results above, we can conclude that $g(n, \gamma)<1$ for all $n \geq 2$ and all $\gamma \leq 3 / 4$. This completes the proof for Corollary 2 .

\footnotetext{
${ }^{14}$ Note that the profit ratio does not depend on the number of centralized firms, $\mathrm{m}$.
} 


\section{Proof of Proposition 2:}

For the first part of the proposition, we need to prove that given any fixed number of other firms adopting centralization, decentralization is more profitable than centralization for each firm. Suppose m-1 other firms are centralized. If a firm chooses centralization then its profit is $\pi_{m, n-m}^{c}$; if it chooses decentralization then its profit is $\pi_{m-1, n-m+1}^{D}$. The ratio of these profits is

$$
\frac{\pi_{m, n-m}^{c}}{\pi_{m-1, n-m+1}^{D}}=\frac{\pi_{m, n-m}^{c}}{\pi_{m, n-m}^{D}} \frac{\pi_{m, n-m}^{D}}{\pi_{m-1, n-m+1}^{D}}=g(n, \gamma) \frac{\pi_{m, n-m}^{D}}{\pi_{m-1, n-m+1}^{D}}
$$

where the last equation uses the definition of $g(n, \gamma)$ in the proof of Corollary 2. From the expression for $\pi_{m, n-m}^{D}$ in Lemma 5 , it is easy to see that $\pi_{m, n-m}^{D}$ decreases in m. Hence $\pi_{m, n-m}^{D}<\pi_{m-1, n-m+1}^{D}$, implying that the ratio in the last term above is less than 1 . From the proof of Corollary 2 , if $\gamma \leq 3 / 4$ then $g(n, \gamma)<1$. Thus, if $\gamma \leq 3 / 4$ then $\frac{\pi_{m, n-m}^{c}}{\pi_{m-1, n-m+1}^{D}}<1$. Obviously this result holds for all $\mathrm{m}$. Hence, $\pi_{m, n-m}^{c}<$ $\pi_{m-1, n-m+1}^{D}$ for all $\mathrm{m}$. That is, for each firm, decentralization strictly dominates centralization.

If all firms adopt centralization the profit of each firm is $\pi_{n, 0}^{c}$; if all firms adopt decentralization the profit of each firm is $\pi_{0, n}^{D}$. The fact (used above) that $\pi_{m, n-m}^{D}$ decreases in m implies that $\pi_{0, n}^{D}>\pi_{m, n-m}^{D}$ for any positive $\mathrm{m}$. From the expression for $\pi_{m, n-m}^{C}$ in Lemma 5 , it is easy to see that $\pi_{m, n-m}^{C}$ also decreases in $\mathrm{m}$. Hence, $\pi_{n, 0}^{c}<\pi_{m, n-m}^{C}$ for all $\mathrm{m}<\mathrm{n}$. It follows that

$$
\frac{\pi_{n, 0}^{c}}{\pi_{0, n}^{D}}<\frac{\pi_{m, n-m}^{c}}{\pi_{m, n-m}^{D}}
$$

By Corollary 2, the right hand side above is less than 1 provided that $\gamma \leq 3 / 4$. Hence, $\pi_{n, 0}^{c}<\pi_{0, n}^{D}$ if $\gamma \leq 3 / 4$. Hence, the dominant-strategy equilibrium in part (1) yields an outcome that is superior to the outcome in which all firms adopt centralization. This proves part (2) of Proposition 2.

\section{Common External Supplier with Uniform Pricing:}

\section{Centralization subgame CC:}

In this subgame, the common external supplier chooses its input price s in stage 2. Given the supplier's price, the two firms then simultaneously choose their outputs $q_{1}$ and $q_{2}$ in stage 3 to solve the following 
problems:

$$
\begin{aligned}
& q_{1}(s)=\operatorname{argmax}_{q_{1}}\left(p_{1}-s-c_{I}\right) q_{1} \\
& q_{2}(s)=\operatorname{argmax}_{q_{2}}\left(p_{2}-s-c_{I}\right) q_{2}
\end{aligned}
$$

The solution from (21) and (22) yields the firms' retail quantities as functions of the supplier price. Anticipating the behaviors of the downstream firms as described by (21) and (22), the external supplier chooses its supplier price as follows:

$$
s=\operatorname{argmax}_{s}\left[\left(s-c_{E}\right) q_{1}(s)+\left(s-c_{E}\right) q_{2}(s)\right]
$$

Substituting the solution to (23) back into the quantity functions (21) and (22) yields the equilibrium output levels. The results are presented in the next lemma.

Lemma 6. In the equilibrium of subgame $\mathrm{CC},{ }^{15}$

1) supplier price is

$$
S^{C C}=\frac{a-c_{I}+c_{E}}{2}
$$

2) retail prices and quantities are

$$
\begin{aligned}
& p_{1}^{C C}=p_{2}^{C C}=\frac{(3+\gamma) a+(1+\gamma)\left(c_{E}+c_{I}\right)}{2(2+\gamma)}, \\
& q_{1}^{C C}=q_{2}^{C C}=\frac{a-c_{E}-c_{I}}{2(2+\gamma)}
\end{aligned}
$$

3) firm profits are

$$
\begin{aligned}
& \pi_{1}^{C C}=\left(p_{1}^{C C}-s_{1}^{C C}-c_{I}\right) q_{1}^{C C}=\frac{\left(a-c_{E}-c_{I}\right)^{2}}{4(2+\gamma)^{2}}, \\
& \pi_{2}^{C C}=\left(p_{2}^{C C}-s_{2}^{C C}-c_{I}\right) q_{2}^{C C}=\frac{\left(a-c_{E}-c_{I}\right)^{2}}{4(2+\gamma)^{2}} .
\end{aligned}
$$

Comparing with the corresponding subgame when firms have exclusive external suppliers (Lemma 1), here the input price charged by the external supplier is higher and the downstream firms earn smaller profits. Obviously, both results are intuitive and are direct consequences of monopoly of the external input by a single

\footnotetext{
${ }^{15}$ To avoid cumbersome notation, we use the same superscripts to denote equilibrium values for subgames in different sections. Given that these values are mainly used within each section, such use will hopefully not cause much confusion.
} 
supplier.

\section{Decentralization subgame DD:}

In this subgame, the common external supplier and the two firms' upper divisions simultaneously choose the supplier price $\mathrm{s}$ and the transfer prices $t_{1}$ and $t_{2}$, respectively, in stage 2 . The lower divisions then choose their outputs $q_{1}$ and $q_{2}$ in state 3 to solve the following problems:

$$
\begin{aligned}
& q_{1}\left(s, t_{1}, t_{2}\right)=\operatorname{argmax}_{q_{1}}\left(p_{1}-s-t_{1}\right) q_{1} \\
& q_{2}\left(s, t_{1}, t_{2}\right)=\operatorname{argmax}_{q_{2}}\left(p_{2}-s-t_{2}\right) q_{2}
\end{aligned}
$$

Anticipating behaviors described by the above functions, the external supplier sets its supplier price $(s)$ and the upper divisions of the two firms choose $t_{1}$ and $t_{2}$, respectively, to solve the following problems:

$$
\begin{aligned}
& s=\operatorname{argmax}_{s}\left[\left(s-c_{E}\right) q_{1}\left(s, t_{1}, t_{2}\right)+\left(s-c_{E}\right) q_{2}\left(s, t_{1}, t_{2}\right)\right] \\
& t_{1}=\operatorname{argmax}_{t_{1}}\left(t_{1}-c_{I}\right) q_{1}\left(s, t_{1}, t_{2}\right) \\
& t_{2}=\operatorname{argmax}_{t_{2}}\left(t_{2}-c_{I}\right) q_{2}\left(s, t_{1}, t_{2}\right)
\end{aligned}
$$

Substituting these values back into the quantity functions (24) and (25) yields the firms' equilibrium retail quantities, transfer prices, supplier price and the profits. These results are presented in the next lemma.

Lemma 7. In the equilibrium of subgame DD,

1) supplier price is

$$
S^{D D}=\frac{2\left(a-c_{I}\right)+(4-\gamma) c_{E}}{6-\gamma}
$$

2) transfer prices, retail prices and quantities are

$$
\begin{aligned}
& t_{1}^{D D}=t_{2}^{D D}=\frac{(2-\gamma) a+4 c_{I}-(2-\gamma) c_{E}}{6-\gamma} \\
& p_{1}^{D D}=p_{2}^{D D}=\frac{\left(10+2 \gamma-\gamma^{2}\right) a+2(1+\gamma)\left(c_{E}+c_{I}\right)}{(2+\gamma)(6-\gamma)} \\
& q_{1}^{D D}=q_{2}^{D D}=\frac{2\left(a-c_{E}-c_{I}\right)}{(2+\gamma)(6-\gamma)}
\end{aligned}
$$

3) firm profits are 


$$
\begin{aligned}
& \pi_{1}^{D D}=\left(p_{1}^{D D}-s^{D D}-c_{I}\right) q_{1}^{D D}=\frac{2\left(6-\gamma^{2}\right)\left(a-c_{E}-c_{I}\right)^{2}}{(2+\gamma)^{2}(6-\gamma)^{2}} \\
& \pi_{2}^{D D}=\left(p_{2}^{D D}-s^{D D}-c_{I}\right) q_{2}^{D D}=\frac{2\left(6-\gamma^{2}\right)\left(a-c_{E}-c_{I}\right)^{2}}{(2+\gamma)^{2}(6-\gamma)^{2}} .
\end{aligned}
$$

Comparing with the corresponding subgame when firms have exclusive external suppliers (Lemma 2), here the input price charged is higher and the downstream firms earn smaller profits. These are direct consequences of the monopoly of the external input. Note that the transfer prices become lower as both firms' upper divisions have to cut transfer prices to stimulate demand from the lower divisions.

Subgame with firm 1 decentralized and firm 2 centralized (DC):

In stage 2, the common external supplier chooses its input price s and firm 1's upper division chooses transfer price $t_{1}$. Given these prices, firm 1 and the lower division of firm 2 in stage 3 choose their outputs $q_{1}$ and $q_{2}$ simultaneously to solve the following problems:

$$
\begin{aligned}
& q_{1}\left(s, t_{1}\right)=\operatorname{argmax}_{q_{1}}\left(p_{1}-s-c_{I}\right) q_{1} \\
& q_{2}\left(s, t_{1}\right)=\operatorname{argmax}_{q_{2}}\left(p_{2}-s-t_{1}\right) q_{2}
\end{aligned}
$$

Anticipating the behaviors as described by (29) to (30), the external supplier chooses $s$ and firm 1's upper division chooses $t_{1}$ to solve the following problems:

$$
\begin{aligned}
& s=\operatorname{argmax}_{s}\left[\left(s-c_{E}\right) q_{1}\left(s, t_{1}\right)+\left(s-c_{E}\right) q_{2}\left(s, t_{1}\right)\right] \\
& t_{1}=\operatorname{argmax}_{t_{1}}\left(t_{1}-c_{I}\right) q_{1}\left(s, t_{1}\right)
\end{aligned}
$$

Solving (31) to (32) jointly, we obtain the equilibrium supplier price and transfer price. Substituting them back into the quantity functions (29) and (30) yields the firms' equilibrium results in subgame DC.

Lemma 8. In the equilibrium of subgame DC,

1) supplier price is

$$
S^{D C}=\frac{(6+\gamma)\left(a-c_{I}\right)+8 c_{E}}{14+\gamma} ;
$$


2) transfer price in firm 1, retail prices and quantities are

$$
\begin{aligned}
& t_{1}^{D C}=\frac{2(2-\gamma)\left(a-c_{E}\right)+(10+3 \gamma) c_{I}}{14+\gamma} \\
& p_{1}^{D C}=\frac{\left(24+8 \gamma-\gamma^{2}\right) a+2\left(2+4 \gamma+\gamma^{2}\right)\left(c_{E}+c_{I}\right)}{(2+\gamma)(14+\gamma)}, \quad p_{2}^{D C}=\frac{\left(20+10 \gamma+\gamma^{2}\right) a+2(4+3 \gamma)\left(c_{E}+c_{I}\right)}{(2+\gamma)(14+\gamma)} \\
& q_{1}^{D C}=\frac{4\left(a-c_{E}-c_{I}\right)}{(2+\gamma)(14+\gamma)}, \quad q_{2}^{D C}=\frac{2(4+\gamma)\left(a-c_{E}-c_{I}\right)}{(2+\gamma)(14+\gamma)}
\end{aligned}
$$

3) firm profits are

$$
\begin{aligned}
& \pi_{1}^{D C}=\left(p_{1}^{D C}-s^{D C}-c_{I}\right) q_{1}^{D C}=\frac{8\left(6-\gamma^{2}\right)\left(a-c_{E}-c_{I}\right)^{2}}{(2+\gamma)^{2}(14+\gamma)^{2}} \\
& \pi_{2}^{D C}=\left(p_{2}^{D C}-s^{D C}-c_{I}\right) q_{2}^{D C}=\frac{4(4+\gamma)^{2}\left(a-c_{E}-c_{I}\right)^{2}}{(2+\gamma)^{2}(14+\gamma)^{2}} .
\end{aligned}
$$

Here the supplier price and retail prices are higher than those in the exclusive external supplier case (Lemma 3). On the other hand, firms' profits, transfer price and retail quantities are lower.

$\underline{\text { Subgame with firm } 1 \text { centralized and firm } 2 \text { decentralized (CD): }}$

Results for subgame CD are immediately obtainable from Lemma 8 by switching the positions between the two firms. Thus we have

Lemma 9. In the equilibrium of subgame CD,

1) supplier price is

$$
S^{C D}=\frac{(6+\gamma)\left(a-c_{I}\right)+8 c_{E}}{14+\gamma} ;
$$

2) transfer price in firm 2, retail prices and quantities are

$$
\begin{aligned}
& t_{2}^{C D}=\frac{2(2-\gamma)\left(a-c_{E}\right)+(10+3 \gamma) c_{I}}{14+\gamma} \\
& p_{1}^{C D}=\frac{\left(20+10 \gamma+\gamma^{2}\right) a+2(4+3 \gamma)\left(c_{E}+c_{I}\right)}{(2+\gamma)(14+\gamma)}, \quad p_{2}^{C D}=\frac{\left(24+8 \gamma-\gamma^{2}\right) a+2\left(2+4 \gamma+\gamma^{2}\right)\left(c_{E}+c_{I}\right)}{(2+\gamma)(14+\gamma)} \\
& q_{1}^{C D}=\frac{2(4+\gamma)\left(a-c_{E}-c_{I}\right)}{(2+\gamma)(14+\gamma)}, \quad q_{2}^{C D}=\frac{4\left(a-c_{E}-c_{I}\right)}{(2+\gamma)(14+\gamma)}
\end{aligned}
$$


3) firm profits are

$$
\begin{aligned}
& \pi_{1}^{C D}=\left(p_{1}^{C D}-s^{C D}-c_{I}\right) q_{1}^{C D}=\frac{4(4+\gamma)^{2}\left(a-c_{E}-c_{I}\right)^{2}}{(2+\gamma)^{2}(14+\gamma)^{2}} \\
& \pi_{2}^{C D}=\left(p_{2}^{C D}-s^{C D}-c_{I}\right) q_{2}^{C D}=\frac{8\left(6-\gamma^{2}\right)\left(a-c_{E}-c_{I}\right)^{2}}{(2+\gamma)^{2}(14+\gamma)^{2}} .
\end{aligned}
$$

\section{Proof of Proposition 3:}

From Lemmas 6-9,

$$
\begin{aligned}
& \pi_{1}^{D C}-\pi_{1}^{C C}=\left[\frac{8\left(6-\gamma^{2}\right)}{(2+\gamma)^{2}(14+\gamma)^{2}}-\frac{1}{4(2+\gamma)^{2}}\right]\left(a-c_{E}-c_{I}\right)^{2}<0, \text { and } \\
& \pi_{1}^{D D}-\pi_{1}^{C D}=\left[\frac{2\left(6-\gamma^{2}\right)}{(2+\gamma)^{2}(6-\gamma)^{2}}-\frac{4(4+\gamma)^{2}}{(2+\gamma)^{2}(14+\gamma)^{2}}\right]\left(a-c_{E}-c_{I}\right)^{2} .
\end{aligned}
$$

For $0 \leq \gamma \leq 0.3708$, we have $\pi_{1}^{D D}-\pi_{1}^{C D}>0$. For $0.3708<\gamma \leq 1$, we have $\pi_{1}^{D D}-\pi_{1}^{C D}<0$. Thus, if $0 \leq \gamma \leq 0.3708$ there are two Nash equilibria: $(\mathrm{C}, \mathrm{C})$ and $(\mathrm{D}, \mathrm{D})$; if $0.3708<\gamma \leq 1$, both firms have a dominant strategy in C. Since

$$
\pi_{1}^{D D}-\pi_{1}^{C C}=\pi_{2}^{D D}-\pi_{2}^{C C}=\frac{3(2-\gamma)(2+3 \gamma)}{4(2+\gamma)^{2}(6-\gamma)^{2}}\left(a-c_{E}-c_{I}\right)^{2}>0
$$

the game is a prisoner's dilemma game for $0.3708<\gamma \leq 1$.

\section{Common External Supplier with Non-uniform Pricing:}

\section{Centralization subgame CC:}

In this subgame, the common external supplier sets its input prices $s_{1}$ and $s_{2}$ in stage 2 . Given the supplier's prices, the two firms simultaneously choose their outputs $\mathrm{q}_{1}$ and $\mathrm{q}_{2}$ in stage 3 to solve the following problems:

$$
\begin{aligned}
& q_{1}\left(s_{1}, s_{2}\right)=\operatorname{argmax}_{q_{1}}\left(p_{1}-s_{1}-c_{I}\right) q_{1} \\
& q_{2}\left(s_{1}, s_{2}\right)=\operatorname{argmax}_{q_{2}}\left(p_{2}-s_{2}-c_{I}\right) q_{2}
\end{aligned}
$$

The solution yields the firms' retail quantities as functions of the prices $s_{1}$ and $s_{2}$. Anticipating the behaviors of the downstream firms, the common supplier decides the supplier prices as follows: 


$$
\left\{s_{1}, s_{2}\right\}=\operatorname{argmax}_{s_{1}, s_{2}}\left[\left(s_{1}-c_{E}\right) q_{1}\left(s_{1}, s_{2}\right)+\left(s_{2}-c_{E}\right) q_{2}\left(s_{1}, s_{2}\right)\right]
$$

Substituting the solution values back into the quantity functions yields the firms' equilibrium quantities.

Lemma 10. The equilibrium of the subgame $\mathrm{CC}$ here is the same as in Lemma 6.

\section{Decentralization subgame DD:}

In this subgame, the common supplier and the two firms' upper divisions simultaneously set the supplier prices $s_{1}$ and $s_{2}$ and the transfer prices $t_{1}$ and $t_{2}$, respectively, in stage 2 . The lower divisions then choose outputs $\mathrm{q}_{1}$ and $\mathrm{q}_{2}$ in stage 3 to play the following quantity game:

$$
\begin{aligned}
& q_{1}\left(s_{1}, s_{2}, t_{1}, t_{2}\right)=\operatorname{argmax}_{q_{1}}\left(p_{1}-s_{1}-t_{1}\right) q_{1} \\
& q_{2}\left(s_{1}, s_{2}, t_{1}, t_{2}\right)=\operatorname{argmax}_{q_{2}}\left(p_{2}-s_{2}-t_{2}\right) q_{2}
\end{aligned}
$$

Anticipating such behaviors, the common supplier sets $s_{1}$ and $s_{2}$, and the upper divisions of the two firms choose $t_{1}$ and $t_{2}$, respectively, to solve the following problems:

$$
\begin{aligned}
& \left\{s_{1}, s_{2}\right\}=\operatorname{argmax}_{s_{1}, s_{2}}\left[\left(s_{1}-c_{E}\right) q_{1}\left(s_{1}, s_{2}, t_{1}, t_{2}\right)+\left(s_{2}-c_{E}\right) q_{2}\left(s_{1}, s_{2}, t_{1}, t_{2}\right)\right] \\
& t_{1}=\operatorname{argmax}_{t_{1}}\left(t_{1}-c_{I}\right) q_{1}\left(s_{1}, s_{2}, t_{1}, t_{2}\right) \\
& t_{2}=\operatorname{argmax}_{t_{2}}\left(t_{2}-c_{I}\right) q_{2}\left(s_{1}, s_{2}, t_{1}, t_{2}\right)
\end{aligned}
$$

The equilibrium supplier prices and transfer prices can be obtained from solving these problems jointly. Plugging the solution values back into the quantity functions above yields the firms' equilibrium retail quantities, transfer prices, supplier prices and the profits.

Lemma 11. The equilibrium of the subgame DD here is the same as in Lemma 7.

Subgame with firm 1 decentralized and firm 2 centralized (DC):

In stage 2, the common supplier sets its input prices $\mathrm{s}_{1}$ and $\mathrm{s}_{2}$, and firm 1's upper division chooses the transfer price $t_{1}$. Given those input prices, the lower division of firm 1 and firm 2 in stage 3 set outputs $\mathrm{q}_{1}$ and 
$\mathrm{q}_{2}$ simultaneously to solve the following problems:

$$
\begin{aligned}
& q_{1}\left(s_{1}, s_{2}, t_{1}\right)=\operatorname{argmax}_{q_{1}}\left(p_{1}-s_{1}-t_{1}\right) q_{1} \\
& q_{2}\left(s_{1}, s_{2}, t_{1}\right)=\operatorname{argmax}_{q_{2}}\left(p_{2}-s_{2}-c_{I}\right) q_{2}
\end{aligned}
$$

Anticipating the behavior as described by these quantity functions, the common supplier sets $\mathrm{s}_{1}$ and $\mathrm{s}_{2}$ and firm 1 's upper division picks $t_{1}$ in the following programs:

$$
\begin{aligned}
& \left\{s_{1}, s_{2}\right\}=\operatorname{argmax}_{s_{1}, s_{2}}\left[\left(s_{1}-c_{E}\right) q_{1}\left(s_{1}, s_{2}, t_{1}\right)+\left(s_{2}-c_{E}\right) q_{2}\left(s_{1}, s_{2}, t_{1}\right)\right] \\
& t_{1}=\operatorname{argmax}_{t_{1}}\left(t_{1}-c_{I}\right) q_{1}\left(s_{1}, s_{2}, t_{1}\right)
\end{aligned}
$$

Solving jointly, we obtain the equilibrium supplier prices and transfer price. Substituting the solution values back into the quantity functions yields the following equilibrium results in subgame DC:

Lemma 12. In the equilibrium of subgame DC,

1) supplier prices are

$$
s_{1}^{D C}=\frac{(4+\gamma)\left(a-c_{I}\right)+(8-\gamma) c_{E}}{12}, \quad S_{2}^{D C}=\frac{a-c_{I}+c_{E}}{2}
$$

2) transfer price in firm 1, retail prices and quantities are

$$
\begin{aligned}
& t_{1}^{D C}=\frac{(2-\gamma)\left(a-c_{E}\right)+(4+\gamma) c_{I}}{6} \\
& p_{1}^{D C}=\frac{\left(20+6 \gamma-\gamma^{2}\right) a+\left(4+6 \gamma+\gamma^{2}\right)\left(c_{E}+c_{I}\right)}{12(2+\gamma)}, \quad p_{2}^{D C}=\frac{(18+7 \gamma) a+(6+5 \gamma)\left(c_{E}+c_{I}\right)}{12(2+\gamma)} ; \\
& q_{1}^{D C}=\frac{a-c_{E}-c_{I}}{3(2+\gamma)}, \quad q_{2}^{D C}=\frac{(6+\gamma)\left(a-c_{E}-c_{I}\right)}{12(2+\gamma)}
\end{aligned}
$$

3) firm profits are

$$
\begin{aligned}
& \pi_{1}^{D C}=\left(p_{1}^{D C}-s_{1}^{D C}-c_{I}\right) q_{1}^{D C}=\frac{\left(6-\gamma^{2}\right)\left(a-c_{E}-c_{I}\right)^{2}}{18(2+\gamma)^{2}} \\
& \pi_{2}^{D C}=\left(p_{2}^{D C}-s_{2}^{D C}-c_{I}\right) q_{2}^{D C}=\frac{(6+\gamma)^{2}\left(a-c_{E}-c_{I}\right)^{2}}{144(2+\gamma)^{2}} .
\end{aligned}
$$

$\underline{\text { Subgame with firm } 1 \text { centralized and firm } 2 \text { decentralized (CD): }}$

Results for subgame $\mathrm{CD}$ are immediately obtainable from Lemma $3 \mathrm{C}$ by switching the positions 
between the two firms.

Lemma 13. In the equilibrium of subgame CD,

1) supplier prices are

$$
s_{1}^{C D}=\frac{a-c_{I}+c_{E}}{2}, \quad s_{2}^{C D}=\frac{(4+\gamma)\left(a-c_{I}\right)+(8-\gamma) c_{E}}{12} ;
$$

2) transfer price in firm 2, retail prices and quantities are

$$
\begin{aligned}
& t_{2}^{C D}=\frac{(2-\gamma)\left(a-c_{E}\right)+(4+\gamma) c_{I}}{6}, \\
& p_{1}^{C D}=\frac{(18+7 \gamma) a+(6+5 \gamma)\left(c_{E}+c_{I}\right)}{12(2+\gamma)}, \quad p_{2}^{C D}=\frac{\left(20+6 \gamma-\gamma^{2}\right) a+\left(4+6 \gamma+\gamma^{2}\right)\left(c_{E}+c_{I}\right)}{12(2+\gamma)}, \\
& q_{1}^{C D}=\frac{(6+\gamma)\left(a-c_{E}-c_{I}\right)}{12(2+\gamma)}, \quad q_{2}^{C D}=\frac{a-c_{E}-c_{I}}{3(2+\gamma)} .
\end{aligned}
$$

3) firm profits are

$$
\begin{aligned}
& \pi_{1}^{C D}=\left(p_{1}^{C D}-s_{1}^{C D}-c_{I}\right) q_{1}^{C D}=\frac{(6+\gamma)^{2}\left(a-c_{E}-c_{I}\right)^{2}}{144(2+\gamma)^{2}} \\
& \pi_{2}^{C D}=\left(p_{2}^{C D}-s_{2}^{C D}-c_{I}\right) q_{2}^{C D}=\frac{\left(6-\gamma^{2}\right)\left(a-c_{E}-c_{I}\right)^{2}}{18(2+\gamma)^{2}}
\end{aligned}
$$




\section{Appendix B: Bertrand Competition}

In this appendix, we examine the base model studied in section 2 under Bertrand price competition. The three-stage game is similar to the one in the base model. In stage 1, firms choose simultaneously between centralization and decentralization. In stage 2, supplier prices and transfer prices (for a decentralized firm) are chosen. In stage 3, retail prices are chosen (by the centralized firm or by the lower division for a decentralized firm). From the inverse demand functions introduced in section 2, we can readily derive the following (direct) demand equations:

$$
\begin{aligned}
& q_{1}=\frac{a}{1+\gamma}-\frac{1}{1-\gamma^{2}} p_{1}+\frac{\gamma}{1-\gamma^{2}} p_{2}, \\
& q_{2}=\frac{a}{1+\gamma}-\frac{1}{1-\gamma^{2}} p_{2}+\frac{\gamma}{1-\gamma^{2}} p_{1} .
\end{aligned}
$$

The following lemmas present results parallel to Lemmas 1-4 in the text. They correspond to the four subgames $(C C, D D, D C, C D)$ following stage 1 of the three-stage game. The key difference between the results reported here and those of Lemmas 1-4 in the text lies in that here the firms engage in Bertrand price competition in the last stage of the game.

In subgame $\mathrm{CC}$, the two exclusive external suppliers first simultaneously set their supplier prices $\mathrm{s}_{1}$ and $s_{2}$, respectively. Given the supplier prices, the two firms then simultaneously choose their retail prices $p_{1}$ and $\mathrm{p}_{2}$, respectively, to maximize their individual profit as follows:

$$
\begin{aligned}
& p_{1}\left(s_{1}, s_{1}\right)=\operatorname{argmax}_{p_{1}}\left(p_{1}-s_{1}-c_{I}\right) q_{1} \\
& p_{2}\left(s_{1}, s_{1}\right)=\operatorname{argmax}_{p_{2}}\left(p_{2}-s_{2}-c_{I}\right) q_{2}
\end{aligned}
$$

Solving these problems jointly, we obtain the firms' retail prices given the supplier prices. Denote their outputs as $q_{1}\left(s_{1}, s_{1}\right)$ and $q_{2}\left(s_{1}, s_{1}\right)$.

In stage 2 of the game, the two exclusive suppliers decide the supplier prices to maximize their individual profits and solve:

$$
\begin{aligned}
& s_{1}=\operatorname{argmax}_{s_{1}}\left(s_{1}-c_{E}\right) q_{1}\left(s_{1}, s_{2}\right) \\
& s_{2}=\operatorname{argmax}_{s_{2}}\left(s_{2}-c_{E}\right) q_{2}\left(s_{1}, s_{2}\right)
\end{aligned}
$$


The solution to these problems yields the equilibrium supplier prices by the outside suppliers. From these equilibrium values and the solutions above we can derive all other equilibrium values as summarized in the following lemma.

Lemma 1B. In the equilibrium of subgame $\mathrm{CC}$,

1) supplier prices are

$$
S_{1}^{C C}=s_{2}^{C C}=\frac{(1-\gamma)(2+\gamma)\left(a-c_{I}\right)+\left(2-\gamma^{2}\right) c_{E}}{4-\gamma-2 \gamma^{2}}
$$

2) retail prices and quantities are

$$
\begin{aligned}
& p_{1}^{C C}=p_{2}^{C C}=\frac{2(1-\gamma)\left(3-\gamma^{2}\right) a+\left(2-\gamma^{2}\right)\left(c_{E}+c_{I}\right)}{(2-\gamma)\left(4-\gamma-2 \gamma^{2}\right)} \\
& q_{1}^{C C}=q_{2}^{C C}=\frac{\left(2-\gamma^{2}\right)\left(a-c_{E}-c_{I}\right)}{(1+\gamma)(2-\gamma)\left(4-\gamma-2 \gamma^{2}\right)}
\end{aligned}
$$

3) firm profits are

$$
\begin{aligned}
& \pi_{1}^{C C}=\left(p_{1}^{C C}-s_{1}^{C C}-c_{I}\right) q_{1}^{C C}=\frac{(1-\gamma)\left(2-\gamma^{2}\right)^{2}\left(a-c_{E}-c_{I}\right)^{2}}{(1+\gamma)(2-\gamma)^{2}\left(4-\gamma-2 \gamma^{2}\right)^{2}} \\
& \pi_{2}^{C C}=\left(p_{2}^{C C}-s_{2}^{C C}-c_{I}\right) q_{2}^{C C}=\frac{(1-\gamma)\left(2-\gamma^{2}\right)^{2}\left(a-c_{E}-c_{I}\right)^{2}}{(1+\gamma)(2-\gamma)^{2}\left(4-\gamma-2 \gamma^{2}\right)^{2}}
\end{aligned}
$$

Similar procedures as those in section 2 are followed in obtaining the next three lemmas for the other three subgames.

Lemma 2B. In the equilibrium of subgame DD,

1) supplier prices are

$$
s_{1}^{D D}=s_{2}^{D D}=\frac{(1-\gamma)(2+\gamma)\left(a-c_{I}\right)+\left(4-\gamma-2 \gamma^{2}\right) c_{E}}{6-2 \gamma-3 \gamma^{2}} ;
$$

2) transfer prices, retail prices and quantities are

$$
\begin{aligned}
& t_{1}^{D D}=t_{2}^{D D}=\frac{(1-\gamma)(2+\gamma)\left(a-c_{E}\right)+\left(4-\gamma-2 \gamma^{2}\right) c_{I}}{6-2 \gamma-3 \gamma^{2}}, \\
& p_{1}^{D D}=p_{2}^{D D}=\frac{(1-\gamma)\left(10-3 \gamma^{2}\right) a+\left(2-\gamma^{2}\right)\left(c_{E}+c_{I}\right)}{(2-\gamma)\left(6-2 \gamma-3 \gamma^{2}\right)},
\end{aligned}
$$




$$
q_{1}^{D D}=q_{2}^{D D}=\frac{\left(2-\gamma^{2}\right)\left(a-c_{E}-c_{I}\right)}{(1+\gamma)(2-\gamma)\left(6-2 \gamma-3 \gamma^{2}\right)}
$$

3) firm profits are

$$
\begin{aligned}
& \pi_{1}^{D D}=\left(p_{1}^{D D}-s_{1}^{D D}-c_{I}\right) q_{1}^{D D}=\frac{2(1-\gamma)\left(2-\gamma^{2}\right)\left(3-\gamma^{2}\right)\left(a-c_{E}-c_{I}\right)^{2}}{(1+\gamma)(2-\gamma)^{2}\left(6-2 \gamma-3 \gamma^{2}\right)^{2}} \\
& \pi_{2}^{D D}=\left(p_{2}^{D D}-s_{2}^{D D}-c_{I}\right) q_{2}^{D D}=\frac{2(1-\gamma)\left(2-\gamma^{2}\right)\left(3-\gamma^{2}\right)\left(a-c_{E}-c_{I}\right)^{2}}{(1+\gamma)(2-\gamma)^{2}\left(6-2 \gamma-3 \gamma^{2}\right)^{2}} .
\end{aligned}
$$

Lemma 3B. In the equilibrium of subgame DC,

1) supplier prices are

$$
\begin{aligned}
& S_{1}^{D C}=\frac{(1-\gamma)(2+\gamma)\left(4+\gamma-2 \gamma^{2}\right)\left(a-c_{I}\right)+\left(16+2 \gamma-17 \gamma^{2}-\gamma^{3}+4 \gamma^{4}\right) c_{E}}{2\left(3-\gamma^{2}\right)\left(4-3 \gamma^{2}\right)}, \\
& s_{2}^{D C}=\frac{(1-\gamma)(2+\gamma)\left(6+2 \gamma-3 \gamma^{2}\right)\left(a-c_{I}\right)+\left(2-\gamma^{2}\right)\left(6+\gamma-3 \gamma^{2}\right) c_{E}}{2\left(3-\gamma^{2}\right)\left(4-3 \gamma^{2}\right)} ;
\end{aligned}
$$

2) transfer price in firm 1, retail prices and quantities are

$$
\begin{aligned}
& t_{1}^{D C}=\frac{(1-\gamma)(2+\gamma)\left(4+\gamma-2 \gamma^{2}\right)\left(a-c_{E}\right)+\left(16+2 \gamma-17 \gamma^{2}-\gamma^{3}+4 \gamma^{4}\right) c_{I}}{2\left(3-\gamma^{2}\right)\left(4-3 \gamma^{2}\right)}, \\
& p_{1}^{D C}=\frac{(1-\gamma)\left(4+\gamma-2 \gamma^{2}\right)\left(10-3 \gamma^{2}\right) a+\left(2-\gamma^{2}\right)\left(4+3 \gamma-3 \gamma^{2}\right)\left(c_{E}+c_{I}\right)}{2(2-\gamma)\left(3-\gamma^{2}\right)\left(4-3 \gamma^{2}\right)}, \quad p_{2}^{D C}=\frac{(1-\gamma)\left(6+2 \gamma-3 \gamma^{2}\right) a+\left(2-\gamma^{2}\right)\left(c_{E}+c_{I}\right)}{(2-\gamma)\left(4-3 \gamma^{2}\right)}, \\
& q_{1}^{D C}=\frac{\left(2-\gamma^{2}\right)\left(4+\gamma-2 \gamma^{2}\right)\left(a-c_{E}-c_{I}\right)}{2(1+\gamma)(2-\gamma)\left(3-\gamma^{2}\right)\left(4-3 \gamma^{2}\right)}, \quad q_{2}^{D C}=\frac{\left(2-\gamma^{2}\right)\left(6+2 \gamma-3 \gamma^{2}\right)\left(a-c_{E}-c_{I}\right)}{2(1+\gamma)(2-\gamma)\left(3-\gamma^{2}\right)\left(4-3 \gamma^{2}\right)} ;
\end{aligned}
$$

3) firm profits are

$$
\begin{aligned}
& \pi_{1}^{D C}=\left(p_{1}^{D C}-s_{1}^{D C}-c_{I}\right) q_{1}^{D C}=\frac{(1-\gamma)\left(2-\gamma^{2}\right)\left(4+\gamma-2 \gamma^{2}\right)^{2}\left(a-c_{E}-c_{I}\right)^{2}}{2(1+\gamma)(2-\gamma)^{2}\left(3-\gamma^{2}\right)\left(4-3 \gamma^{2}\right)^{2}}, \\
& \pi_{2}^{D C}=\left(p_{2}^{D C}-s_{2}^{D C}-c_{I}\right) q_{2}^{D C}=\frac{(1-\gamma)\left(2-\gamma^{2}\right)^{2}\left(6+2 \gamma-3 \gamma^{2}\right)^{2}\left(a-c_{E}-c_{I}\right)^{2}}{4(1+\gamma)(2-\gamma)^{2}\left(3-\gamma^{2}\right)\left(4-3 \gamma^{2}\right)^{2}} .
\end{aligned}
$$

Lemma 4B. In the equilibrium of subgame CD,

1) supplier prices are

$$
\begin{aligned}
& S_{1}^{C D}=\frac{(1-\gamma)(2+\gamma)\left(6+2 \gamma-3 \gamma^{2}\right)\left(a-c_{I}\right)+\left(2-\gamma^{2}\right)\left(6+\gamma-3 \gamma^{2}\right) c_{E}}{2\left(3-\gamma^{2}\right)\left(4-3 \gamma^{2}\right)}, \\
& S_{2}^{C D}=\frac{(1-\gamma)(2+\gamma)\left(4+\gamma-2 \gamma^{2}\right)\left(a-c_{I}\right)+\left(16+2 \gamma-17 \gamma^{2}-\gamma^{3}+4 \gamma^{4}\right) c_{E}}{2\left(3-\gamma^{2}\right)\left(4-3 \gamma^{2}\right)}
\end{aligned}
$$


2) transfer price in firm 2 , retail prices and quantities are

$$
\begin{aligned}
& t_{2}^{C D}=\frac{(1-\gamma)(2+\gamma)\left(4+\gamma-2 \gamma^{2}\right)\left(a-c_{E}\right)+\left(16+2 \gamma-17 \gamma^{2}-\gamma^{3}+4 \gamma^{4}\right) c_{I}}{2\left(3-\gamma^{2}\right)\left(4-3 \gamma^{2}\right)} \\
& p_{1}^{C D}=\frac{(1-\gamma)\left(6+2 \gamma-3 \gamma^{2}\right) a+\left(2-\gamma^{2}\right)\left(c_{E}+c_{I}\right)}{(2-\gamma)\left(4-3 \gamma^{2}\right)}, \quad p_{2}^{C D}=\frac{(1-\gamma)\left(4+\gamma-2 \gamma^{2}\right)\left(10-3 \gamma^{2}\right) a+\left(2-\gamma^{2}\right)\left(4+3 \gamma-3 \gamma^{2}\right)\left(c_{E}+c_{I}\right)}{2(2-\gamma)\left(3-\gamma^{2}\right)\left(4-3 \gamma^{2}\right)} \\
& q_{1}^{C D}=\frac{\left(2-\gamma^{2}\right)\left(6+2 \gamma-3 \gamma^{2}\right)\left(a-c_{E}-c_{I}\right)}{2(1+\gamma)(2-\gamma)\left(3-\gamma^{2}\right)\left(4-3 \gamma^{2}\right)}, \quad q_{2}^{C D}=\frac{\left(2-\gamma^{2}\right)\left(4+\gamma-2 \gamma^{2}\right)\left(a-c_{E}-c_{I}\right)}{2(1+\gamma)(2-\gamma)\left(3-\gamma^{2}\right)\left(4-3 \gamma^{2}\right)}
\end{aligned}
$$

3) firm profits are

$$
\begin{aligned}
& \pi_{1}^{C D}=\left(p_{1}^{C D}-s_{1}^{C D}-c_{I}\right) q_{1}^{C D}=\frac{(1-\gamma)\left(2-\gamma^{2}\right)^{2}\left(6+2 \gamma-3 \gamma^{2}\right)^{2}\left(a-c_{E}-c_{I}\right)^{2}}{4(1+\gamma)(2-\gamma)^{2}\left(3-\gamma^{2}\right)\left(4-3 \gamma^{2}\right)^{2}} \\
& \pi_{2}^{C D}=\left(p_{2}^{C D}-s_{2}^{C D}-c_{I}\right) q_{2}^{C D}=\frac{(1-\gamma)\left(2-\gamma^{2}\right)\left(4+\gamma-2 \gamma^{2}\right)^{2}\left(a-c_{E}-c_{I}\right)^{2}}{2(1+\gamma)(2-\gamma)^{2}\left(3-\gamma^{2}\right)\left(4-3 \gamma^{2}\right)^{2}}
\end{aligned}
$$

These lemmas lend support to similar conclusions to those we made in the text following Lemmas 1-4. In turn we have the following proposition that parallels the results in Proposition 1. It confirms that price competition in the product market yields similar results as in the base model with quantity competition.

Proposition 1B. The following results hold in equilibrium when the two firms have exclusive external suppliers and engage in Bertrand price competition.

(1) Decentralization is the dominant strategy for both firms for all $\gamma \in[0,1]$.

(2) The game is an efficient dominant-strategy game.

Proof: In stage one, each firm chooses between centralization (C) and decentralization (D). The reduced game for stage 1 of the 3 -stage game is represented by the following matrix:

Firm 2

Firm 1

\begin{tabular}{|c|c|c|}
\hline & $\mathrm{C}$ & $\mathrm{D}$ \\
\hline $\mathrm{C}$ & $\left(\pi_{1}^{C C}, \pi_{2}^{C C}\right)$ & $\left(\pi_{1}^{C D}, \pi_{2}^{C D}\right)$ \\
\hline $\mathrm{D}$ & $\left(\pi_{1}^{D C}, \pi_{2}^{D C}\right)$ & $\left(\pi_{1}^{D D}, \pi_{2}^{D D}\right)$ \\
\hline
\end{tabular}


Using results in Lemmas 1B-4B,

$$
\begin{aligned}
& \pi_{1}^{D C}-\pi_{1}^{C C}=\frac{(1-\gamma)\left(2-\gamma^{2}\right)\left(64-96 \gamma^{2}+37 \gamma^{4}+2 \gamma^{6}-2 \gamma^{8}\right)\left(a-c_{E}-c_{I}\right)^{2}}{2(1+\gamma)(2-\gamma)^{2}\left(3-\gamma^{2}\right)\left(4-3 \gamma^{2}\right)^{2}\left(4-\gamma-2 \gamma^{2}\right)^{2}}>0 \\
& \pi_{1}^{D D}-\pi_{1}^{C D}=\frac{(1-\gamma)\left(2-\gamma^{2}\right)\left(864-1584 \gamma^{2}+904 \gamma^{4}-112 \gamma^{6}-42 \gamma^{8}+9 \gamma^{10}\right)\left(a-c_{E}-c_{I}\right)^{2}}{4(1+\gamma)(2-\gamma)^{2}\left(3-\gamma^{2}\right)\left(4-3 \gamma^{2}\right)^{2}\left(6-2 \gamma-3 \gamma^{2}\right)^{2}}>0 .
\end{aligned}
$$

Hence, firm 1 has a dominant strategy in D. By symmetry, firm 2 also has a dominant strategy in D. Thus, the unique Nash equilibrium of the above matrix game is (D, D). Since, by Lemmas 1B and 2B,

$$
\pi_{1}^{D D}-\pi_{1}^{C C}=\pi_{2}^{D D}-\pi_{2}^{C C}=\frac{(1-\gamma)(2+\gamma)\left(2-\gamma^{2}\right)\left(12-6 \gamma-8 \gamma^{2}+2 \gamma^{4}+\gamma^{5}\right)\left(a-c_{E}-c_{I}\right)^{2}}{4(1+\gamma)(2-\gamma)^{2}\left(3-\gamma^{2}\right)\left(4-3 \gamma^{2}\right)^{2}\left(6-2 \gamma-3 \gamma^{2}\right)^{2}}>0
$$

the game is one with an efficient dominant-strategy equilibrium. 


\section{References}

Armstrong, Mark, John Vickers and Jidong Zhou (2009) "Prominence and Consumer Search," The Rand Journal of Economics, Vol. 40, No. 2, pp. 209-233.

Arya, Anil and Brian Mittendorf (2007) "The Pricing of Internal Transfers and External Procurement," The Accounting Review, Vol. 82, pp. 551-580.

Coughlan, Anne (1985) "Competition and Cooperation in Marketing Channel Choice: Theory and Application,” Marketing Science, Vol. 4, No.2, pp.110-129.

Gupta, Sudheer and Richard Loulou (1998) "Process Innovation, Product Differentiation, and Channel Structure: Strategic Incentives in a Duopoly,” Marketing Science, Vol. 17, No. 4, pp. 301-316.

Jerath, Kinshuk. and Z. John Zhang (2010) "Store-within-a-Store," Journal of Marketing Research, forthcoming.

McGuire, Timothy and Richard Staelin (1983) "An Industry Equilibrium Analysis of Downstream Vertical Integration," Marketing Science, Vol. 2, No. 2, pp. 161-191.

Rey, Patrick and Joseph Stiglitz (1995) "The Role of Exclusive Territories in Producers' Competition," The Rand Journal of Economics, Vol. 26, No.3, pp. 431-451.

Spengler, Joseph J. (1950) "Vertical Integration and Antitrust Policy," Journal of Political Economy, Vol 58, No. 4, pp. 347-252.

Trivedi, Minakshi (1998) "Distribution Channels: An Extension of Exclusive Retailership," Management Science, Vol. 44, pp. 896-909.

Wang, Chih-Jen, Ying-Ju Chen and Chi-Cheng Wu (2010) "Advertising Competition and Industry Channel Structure," Marketing Letters, forthcoming.

Wang, X. H. and Bill Yang (2003) "Classification of $2 \times 2$ Games and Strategic Business Behavior," American Economist, Vol. 47, No. 2, pp. 78-85. 